
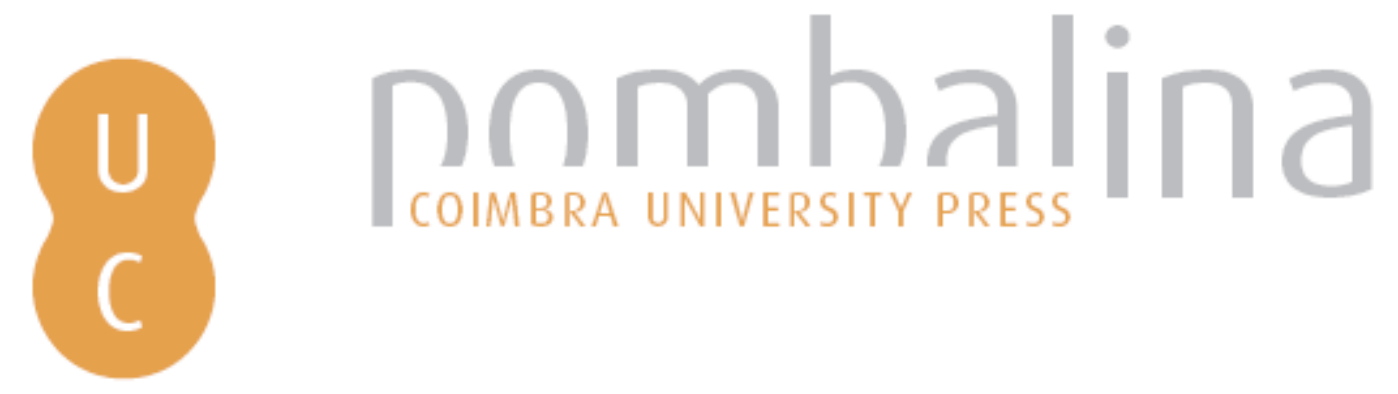

\title{
A tradição manuscrita do Lucullllus de Cícero: do corpus Leidense a William de Malmesbury e à fortuna no período humanístico
}
Autor(es):
Malaspina, Ermanno
Publicado por: Imprensa da Universidade de Coimbra
URL
persistente:
URI:http://hdl.handle.net/10316.2/45197
DOI:
DOI:https://doi.org/10.14195/978-989-26-1671-1_1
Accessed : $\quad$ 12-Feb-2019 06:25:22

A navegação consulta e descarregamento dos títulos inseridos nas Bibliotecas Digitais UC Digitalis, UC Pombalina e UC Impactum, pressupõem a aceitação plena e sem reservas dos Termos e Condições de Uso destas Bibliotecas Digitais, disponíveis em https://digitalis.uc.pt/pt-pt/termos.

Conforme exposto nos referidos Termos e Condições de Uso, o descarregamento de títulos de acesso restrito requer uma licença válida de autorização devendo o utilizador aceder ao(s) documento(s) a partir de um endereço de IP da instituição detentora da supramencionada licença.

Ao utilizador é apenas permitido o descarregamento para uso pessoal, pelo que o emprego do(s) título(s) descarregado(s) para outro fim, designadamente comercial, carece de autorização do respetivo autor ou editor da obra.

Na medida em que todas as obras da UC Digitalis se encontram protegidas pelo Código do Direito de Autor e Direitos Conexos e demais legislação aplicável, toda a cópia, parcial ou total, deste documento, nos casos em que é legalmente admitida, deverá conter ou fazer-se acompanhar por este aviso.

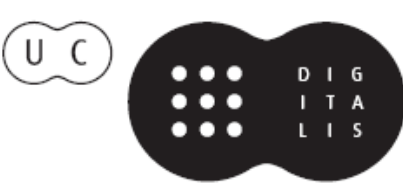




\section{Cícero: \\ obra e recepção}

Isabella Tardin Cardoso, Marcos Martinho (coords.) 


\title{
A tradição manuscrita do LuCullus de Cícero: do coRpus LEIDENSE A William de Malmesbury e À Fortuna NO PERÍODO HUMANÍSTICO ${ }^{1}$ \\ (The manuscript tradition of Cicero's Lucullus: from the corpus Leidense down to William of Malmesbury and its fortune during the Humanism)
}

\author{
Ermanno Malaspina (ermanno.malaspina@unito.it) \\ Università di Torino
}

\begin{abstract}
Resumo: Propor o estema dos recentiores de Wien, Öster. Nationalbibl., 189 (V) para o Lucullus ciceroniano esclarece a história da tradição e volta a atenção sobre o SaintOmer, Bibl. Munic., 652, até agora não reconhecido como gêmeo de Cambridge, Univ. Libr., Dd.XIII.2, e fruto de um extraordinário trabalho textual de William de Malmesbury no século XII. Graças a quatro lacunas maiores ( $\S 28,28,106,144)$, os apógrafos estão reagrupados em classes, e, entre esses, estão identificados aqueles a que recorrer para reconstruir o texto de $\mathbf{V}$, corrigido por $\mathbf{V}^{2}$, nos $\S \S 104-48$ faltantes, em complemento a Paris, B.N.F., lat. 17812, o único presente no aparato Plasberg.

Palavras-Chave: Lucullus; edição crítica.
\end{abstract}

Aвstract: Presenting a stemma for the descendants of Wien, Öster. Nationalbibl., 189 (V) in Cicero's Lucullus sheds light on the history of the tradition and reveals the importance of Saint-Omer, Bibl. Munic., 652, not yet identified as a gemellus of

\footnotetext{
${ }^{1} \mathrm{O}$ presente artigo retoma só em parte os assuntos de que eu havia tratado no dia 31 de maio de 2012, em meu relatório apresentado em colóquio na USP, intitulado $A$ tradição manuscrita do Lucullus de Cícero: novas descobertas, aprofundando sobretudo a tradição recentior. Sou grato à comissão organizadora do colóquio Ciceronianissimos pelo convite e a Izabella Lombardi Garbellini pela tradução em português, mas também sinto a obrigação de assinalar os muitos amigos e colegas que acompanharam a gestação destas páginas no verão de 2013. Rémy Cordonnier, diretor dos Fundos Antigos e dos Arquivos da Biblioteca de Saint-Omer, verificou, a meu pedido, alguns elementos diretamente no manuscrito 652 , resolvendo também o problema de datação com competência e amabilidade louváveis. Não me surpreendeu que a descoberta de novidades relevantes, penso eu, a respeito de uma glória da Inglaterra como William de Malmesbury tenha atraído o interesse de três excelsos colegas anglófonos, entre a Tasmânia, Princeton e Cambridge, e comoveram-me o seu entusiasmo, a sua curiosidade intelectual e a sua disponibilidade para cooperar: agradeço a Rod Thomson por seu interesse, suas observações e notas de leitura sobre as minhas páginas; Bob Kaster generosamente enviou-me um de seus trabalhos ainda no prelo, fornecendo-me um indício preciosíssimo para definir os procedimentos utilizados por "William at work"; a Michael Reeve, quae eius est et suavitas et doctrina, devo uma leitura profunda e riquíssima em ideias de uma primeira versão destas páginas, bem como uma troca de e-mail para mim decisiva, não só a respeito de William, e uma revisão final com os olhos de Linceu. Finalmente, Giovanna Garbarino e Giuseppina Magnaldi leram uma versão intermediária do trabalho, e Andrea Balbo leu tanto essa quanto a definitiva, fazendo-lhes correções valiosas: quero expressar minha gratidão a todos, seguro de que sou eu o único responsável por imprecisões ou omissões. A tradução contou com a revisão técnica do Prof. Dr. Paulo Sérgio de Vasconcellos (UNICAMP).
} 
Cambridge, Univ. Libr., Dd.XIII.2, both the result of unusually intensive work done on the text by William of Malmesbury in the 12th century. Thanks to four major lacunae ( $\S 28,28,106,144)$, the manuscripts are assigned to four classes and those manuscripts picked out that can serve alongside Paris, B.N.F., lat. 17812, the only one cited in Plasberg's apparatus, for reconstructing in $\S \S 104-48$ the missing text of $\mathbf{V}$ as corrected by $\mathbf{V}^{2}$.

KeYwords: Lucullus; critical edition.

\section{O status QUAESTIONIS}

O Lucullus aguarda uma nova edição crítica desde 1908, quando O. Plasberg dedicou-se, quanto pôde, à publicação desse e de alguns outros tratados ciceronianos, com uma editio maior à qual seguiram editiones minores mais simples (sobretudo no aparato). O Luc. ${ }^{3}$ foi publicado em 1922 (junto aos Academici), 14 anos após a maior e há mais de 90 anos. Esta foi a primeira e a única vez em que o texto do tratado foi editado com base em um rigoroso exame autóptico dos manuscritos antiquiores: sem nada subtrair da genialidade e dos méritos de filólogos como Lambin, Davis, Müller, Madvig ou Reid, anteriores a Plasberg, ou como Rackham, Haltenhoff, Straume-Zimmermann, Riganti, Schäublin ou Brittain, após Plasberg, foi somente este último a conduzir sobre os testemunhos carolíngios um exame codicológico e paleográfico sistemático, que permanece ainda hoje o ponto de partida imprescindível e talvez insuperável.

É lógico, portanto, que uma nova edição que parta novamente dos manuscritos seja considerada uma necessidade ${ }^{4}$ : além do tempo que passa, há duas ulteriores considerações concernentes à história de pesquisa sobre o Luc.: do ponto de vista filosófico e conteudístico, a nova época de estudos, aberta por Carlos Lévy $^{5}$, torna necessário assegurar uma base textual firme a um tratado que fora de fato reinterpretado sob muitos aspectos; do ponto de vista filológico, então, a falta de edições do Luc. capazes de substituir a de Plasberg não significou a falta

${ }^{2}$ Reduzida no número de obras no que concerne às intenções: somente Paradoxa, Academici, Lucullus, Timaeus, De natura deorum, enquanto o vol. III, que contém De divinatione, De fato, nunca foi publicado.

${ }^{3}$ Por clareza, em meu texto, uso sempre a forma Luc(ullus), mantendo Acadêmicas para os fragmentos da versão em quatro livros, que sobreviveram através de uma tradição bastante diversa e não são objeto de minha pesquisa. Presumo que a gênese das Acadêmicas seja conhecida, da primeira edição em dois livros (o segundo dos quais é precisamente o Luc.) àquela definitiva: indicações cronológicas e bibliografia básica ad loc. nas Ephemerides Tullianae (http://www.tulliana.eu/ephemerides/testi/45/academ.htm).

${ }^{4} \mathrm{O}$ grupo de pesquisa liderado por Carlos Lévy e composto por Terence Hunt, para a obra Acadêmicas, e por mim, para a obra Luc., publicará dentro de algum tempo uma edição crítica bilíngue com tradução francesa e comentário pela série CUF das edições "Belles Lettres".

${ }^{5}$ Hoje disponível gratuitamente on-line em .pdf no site da SIAC (www.tulliana.eu): em relação à situação, cf. Malaspina, 2013. 
do interesse pela edótica de Cícero filósofo. Uma série de estudos e edições de valor constitui hoje um cenário muito interessante e inovador no qual localizar, finalmente, uma edição crítica também do Luc. Refiro-me às edições prestigiosas como a dos Paradoxa, sob os cuidados de R. Badalì, os Topica, de T. Reinhardt, até o recente De legibus, de J.G.F. Powell. Preciosíssimas, ainda que relativas a obras da tradição independente (ao menos quanto aos ramos mais antigos), são as duas edições do De finibus, de C. Moreschini e de L.D. Reynolds, de organização ${ }^{6}$ bem diversa. Enfim, a análise filológica pode ser baseada em monografias sistemáticas de grande valor, como a pesquisa sobre códices do De legibus, de P.L. Schmidt, e dos Academici, do já citado T. Hunt (a ambos as minhas modestas pesquisas devem muitíssimo): tais trabalhos, que levam em consideração a tradição até os testemunhos mais recentes e os incunábulos, requerem e juntos auxiliam uma pesquisa filológica similar também para o Luc., atenta à terra incognita dos recentiores segundo os hábitos da moderna história da tradição7.

Todavia, que o quadro interpretativo não é compartilhado nem pelos antiquiores é demonstrado pela estimulante contribuição de M. Zezler e K. Zezler, que reabre a questão da valoração das intervenções do período carolíngio e de sua natureza de conjecturas ope ingenii, como é sustentado por Plasberg, em vez de lições de tradição independente.

Antes de prosseguir, é necessário introduzir algumas palavras de contextualização sobre o Corpus Leidense, o conjunto de oito tratados ciceronianos ${ }^{8}$ que garantiu a transmissão do $L u c$. e que é constituído por três testemunhos carolíngios, $\mathbf{B A V}^{9}$, dos quais todos os outros ${ }^{10}$ derivam: as minhas colações confirmam, de fato, que as lições dos testemunhos atualmente disponíveis são apenas corrupções em diversos níveis do texto de BAV, ou seja, o fruto das intervenções ope ingenii, mais ou menos felizes, dos sete séculos sucessivos de tradição manuscrita. Como não me ocupo neste estudo da questão das relações recíprocas entre esses três, limito-me a recordar que é opinião majoritária que $\mathbf{A}$ e $\mathbf{V}$ estão mais estreitamente ligados, dependendo de um subarquétipo comum, e que, portanto, a sua lição se contrapõe à do $\mathbf{B}$ isolado ${ }^{11}$.

Imediatamente sucessivos a esses três testemunhos, localizam-se por

${ }^{6}$ Para uma análise atualizada, cf. Magnaldi, 2007.

${ }^{7}$ Cf. Malaspina, 2011, p. 548, e Malaspina et Al., 2014, n. 5.

${ }^{8} \mathrm{Na}$ ordem de A, De natura deorum, De divinatione, Timaeus, De fato, Topica, Paradoxa, Luc. e De legibus (B tem o Timaeus deslocado para o fim, após o De legibus, enquanto $\mathbf{V}$ antecipa-o, colocando-o após o De natura deorum, e não apresenta os Topica, além do final, cf. infra $\S 3$ ).

${ }_{9}^{9}$ No fim do artigo, está presente para a comodidade do leitor o conspectus siglorum. Dentre os protótipos do Corpus Leidense, encontra-se também $\mathbf{H}$, que, todavia, não contém o Luc.; só para este tratado acrescenta-se $\mathbf{S}$, um recentior (séc. XIV) muito próximo a $\mathbf{V}^{\mathbf{1}}$ e até agora nunca considerado pelos editores (dele trato em Malaspina, em preparação).

${ }^{10}$ Cf. infra n. 18.

${ }^{11}$ Cf. Halm, 1850, Schmidt, 1974, p. 27-121, Rouse, 1983, e Malaspina, em preparação. 
antiquidade $\mathbf{F}$ (séc. IX), $\mathbf{N}$ (séc. XII) e T (sécs. XII-XIII), todavia de importância diversa. $\mathrm{O}$ esplêndido $\mathbf{F}$ é fruto de um imponente trabalho de colação e correção recíproca $\mathbf{B}>\mathbf{A}$ e $\mathbf{A}>\mathbf{B}$ em Corbie. Sua descoberta, em Estrasburgo, por Poggio Bracciolini, por volta de 1417, tornou-o o protótipo da tradição humanística florentina, que chega a mais de quinze exemplares, caracterizados por substancial aderência a $\mathbf{F}$, por sua vez, cópia muito fiel de $\mathbf{B} \mathbf{A}^{12}$.

\section{TEMA DO PRESENTE ESTUDO}

Dentre as diversas pistas de pesquisa disponíveis para o editor do $L u c$., dedico estas páginas à descendência do códice $\mathbf{V}$ : graças às colações até agora realizadas, de maneira quase sempre autóptica, sobre todos os testemunhos conhecidos, é-me possível enquadrar essa tradição em classes, segundo o método tradicional dos errores coniunctivi e disiunctivi, com importância e espaço decrescentes à medida que os recentiores se distanciam do protótipo e veem consequentemente aumentar corrupções e contaminções. As dimensões de um artigo não permitem, contudo, realizar um stemma completo, comparável ao proposto por P.L. Schmidt para o De legibus, com a apresentação de cada testemunho e a definição precisa dos vínculos de dependência. Todavia, é minha intenção chegar, no futuro, a esse resultado, dentro de um exame orgânico e monográfico da história completa do texto do $L u c$., a respeito do qual estas páginas constituem um estudo preparatório ${ }^{13}$.

\section{A tradição bipartida de $V$}

A opinião comum é que "from $V$ descend the majority of late medieval and Renaissance manuscripts of Cicero's philosophical works"14, uma derivação para nós complicada pelo fato que $\mathbf{V}$ se apresenta ao menos desde o século XVI sem os cadernos sucessivos àquele marcado XX, ou seja, do último terço do $L u c$. (§§ 104-48) e de todo o De legibus, com o qual V, como A, se concluía. O processo de cópia, obviamente conduzido quando $\mathbf{V}$ ainda era íntegro, produziu para todos os tratados do Corpus Leidense uma selva de apógrafos mais antigos que

${ }^{12}$ Sobre F permanece insuperado Schmidt, 1974, p. 121-61; sobre a tradição, por fim, Malaspina et A1., 2014, p. 593-612.

${ }^{13}$ Para completar com outros quatro: um, já disponível (Malaspina, 2011), contém o elenco e uma subdivisão básica de todos os manuscritos, importante, sobretudo, para os recentiores, uma vez que, como já se disse, os protótipos da tradição ainda são os mesmos de Plasberg (com um acréscimo, cf. supra n. 9); Malaspina et Al, 2014, é centrado nos recentiores da Biblioteca Apostólica Vaticana, que por si só representam mais da metade da descendência de $\mathbf{F}$ (da qual, consequentemente, não trato aqui). Com Malaspina, em preparação, de fato, volto aos protótipos, com um exame sistemático funcional para a constitutio textus.

${ }^{14}$ Rouse, 1983, p. 126. 
aqueles de $\mathbf{F}$, que são, na verdade, posteriores, como se disse, a 1417: nenhum desses mantém a consistência e a ordem original do Corpus Leidense ${ }^{15}$, com a consequência de que a tradição recentior de cada obra se baseia em uma bateria própria de manuscritos, que só em parte coincidem com os dos outros tratados. Consequência ulterior, desencorajadora para o estudioso, é que o trabalho já realizado por outros ${ }^{16}$ só em alguns casos pode ser válido para o Luc. sem modificações, visto que, até mesmo onde os dois tratados do Corpus Leidense comparecem novamente no mesmo recentior, a reconstrução sistemática válida para um não é a mesma necessarimente para o outro ${ }^{17}$.

Os códices atribuíveis à descendência de $\mathbf{V}$ são 35 , compreendidos $\mathbf{N T}$ e excluídos por simplicidade aqueles que referem somente excerpta ${ }^{18}$. Melhor que me basear no complexo estema de $\mathrm{Schmidt}^{19}$ e buscar adaptar a realidade do $D e$

${ }^{15}$ Cf. supra n. 8.

${ }^{16}$ Refiro-me, em particular, às monografias já citadas de P.L. Schmidt, sobre o De Legibus, e de T.J. Hunt, sobre as Acadêmicas (obra que, embora não pertença, como mencionado, ao Corpus Leidense, compartilha de quase metade dos recentiores do Luc.). Muito mais superficial - e, por vezes, imprecisa - é a reconstrução estemática que van den Bruwaene, 1970, p. 34-42, propôs em sua edição do Livro I do De natura deorum.

${ }^{17}$ Acreditamos, por exemplo, ter demonstrado (em Malaspina et A1., 2014, p. 602-4) que, para o Luc., Reg foi modelado sobre F, sem intermediários, diferentemente do que ocorreu com o De Legibus, pelo qual Reg é uma cópia de Vat4, por sua vez, cópia direta de $\mathbf{F}$ (Schmidt, 1974, p 287-96): como havíamos escrito (p. 603), "una ricostruzione stemmatica diversa o anche antitetica per il $\mathrm{Luc}$. rispetto a quanto sostenuto da altri studiosi per altri trattati all'interno di un medesimo codice non comporta la messa in dubbio automatica o la critica implicita delle tesi altrui, ma solo l'ennesima dimostrazione che un singolo manoscritto può essere portatore di tradizioni diverse anche per opere dalla vicenda testuale apparentemente parallela”.

${ }^{18}$ A lista dos 74 manuscritos hoje identificados encontra-se em Malaspina, 2011, p. 54952, a ser completada com Neap2, os excerpta de Mon3 e aqueles brevíssimos de Cas (todos do séc. XV, cf. também Malaspina et A1., 2014, n. 10). Excluindo os protótipos BAVSF, temos 8 recentiores que contêm apenas excerpta, 25 descendentes de $\mathbf{F}$ e, justamente, 35 de V. A única incógnita é Chris, vendido em leilão no dia 25 de junho de 1986, cujas lições são completamente desconhecidas (cf. ainda Malaspina, 2011, n. 10). Os 35 testemunhos objeto deste estudo são aqueles elencados em Malaspina, 2011, p. 553-4, ao qual é acrescentado o já referido Neap2 e são subtraídos tanto $\mathbf{S}$ (cf. supra n. 9) quanto Linc e Par3: em um primeiro momento, eu havia, de fato, atribuído os dois últimos à família de $\mathbf{V}$, com base na autoridade de Schmidt, 1974 (respectivamente p. 240-5 e p. 316-9), que, em relação ao De legibus, considera ambos descendentes ao longo do ramo $p$ (cf. infra n. 92), o qual passou no século XIV da biblioteca de Avignon para a Itália aos cuidados de Petrarca. No entanto, um exame sem prejulgamento negativo de suas lições demostra para o Luc. a dependência absoluta de F e, em particular, de Vat4, de cuja facies muito peculiar (cf. infra n. 20, e Malaspina et Al., 2014, p. 595-9) dependem as coincidências ocasionais com V.

${ }_{19}$ Schmidt identifica uma família $\mathbf{w}$ distinta de $\mathbf{V}$, à qual também pertencem $\mathbf{G u d}$ e Trec (que, ao contrário, em relação ao Luc., como veremos, descendem de $\mathbf{V}$ sem peculiaridades específicas, cf. $\S 4.5$ e n. 55); tal estema, no entanto, não teve a colaboração dos editores posteriores (cf. Powell, 2006, p. XXXVIII-XLVIII). Dentre os apógrafos regulares de V, os casos em que a localização estemática válida para o De legibus é confirmada no Luc. reduzemse ao grupo de Gadd (cf. infra § 4.3). Resumido e pouco confiável é o estema que van den 
legibus ao Luc., considero metodologicamente mais correto e ainda mais fácil partir do zero, nisso facilitado pela raridade das contaminações com a família de $\mathbf{F}^{20}$. Digamos logo que os descendentes de $\mathbf{V}$ aparecem claramente bipartidos em dois grupos, dos quais um, que indico com a sigla $\mathbf{m}$, é formado somente por Bert e Cant2, e o outro, v, compreende todos os outros e, como veremos, deixa-se ulteriormente subdividir em seu interior. Seja $\mathbf{m}$ ou $\mathbf{v}$, ambos apresentam até o § 104 as principais características de $\mathbf{V}$ (corrigido por $\mathbf{V}^{2}$ ), em oposição a $\mathbf{B A}$, das quais apresento aqui pouquíssimos casos exempli gratia:

1) 1 om. urbanis $\mathbf{V}_{\mathbf{v m}}: 3$ ita $\mathbf{B} \mathbf{A V ^ { 1 }}$ itaque $\mathbf{V}^{2} \mathbf{v m}$ : 7 facilis $\mathbf{B A}$ facilior $\mathbf{V} \mathbf{v m}$ : et audiendo om. $\mathbf{V v m}$ : 9 omnia $\mathbf{B} A \mathbf{V}^{1}$ omnino $\mathbf{V}^{2} \mathbf{v m}$ : saepe nobis $\mathbf{B A}$ saepe $\mathbf{V v m}: 20$ quin $\mathbf{B} \mathbf{A}^{1 \mathbf{1}} \mathbf{V}^{\mathbf{1}} \mathbf{F}$ qui non $\mathbf{A}^{2} \mathbf{V}^{2} \mathbf{v m}{ }^{21}$ : nos om. $\mathbf{V} \mathbf{v m}: 38$ quamquam si $\mathbf{B A V}^{1}$ quamquam $\mathbf{V}^{2} \mathbf{v m}: 47$ a Stoicis $\mathbf{B A}$ Stoicis $\mathbf{V v m}$ : aut si ea quoque possit, cur illa non possit om. Vvm : 58 iudicem om. Vvm : 62 illarum quoque rerum $\mathbf{B A}$ illa rerum quoque rerum $\mathbf{V}^{1}$ illa rerum quoque $\mathbf{V}^{2} \mathbf{v m}: 67$ ab iis quae possint om. $\mathbf{V v m}: 84$ videri $\mathbf{B A}$ videre $\mathbf{V v m}:$ tibi videbitur $\mathbf{B A}$ tibi videtur $\mathbf{V}_{\mathbf{v m}}$ : 88 eum somniare $\mathbf{B} \mathbf{A} \mathbf{V}^{1}$ eum somnia $\mathbf{V}^{2} \mathbf{v m}: 89$ licet $\mathbf{B A}$ dicet $\mathbf{V}^{1}$ dicit $\mathbf{V}^{2} \mathbf{v m}: 97$ enim inquit alterutrum om. $\mathbf{V v m}: 100$ capiet om. $\mathbf{V} \mathbf{v m}{ }^{22}$

\section{A Classe DE $v$}

\subsection{O problema de $\mathrm{N}$}

Ocupar-nos-emos de $\mathbf{m}$ no $\S 5$, enquanto nos concentramos aqui nos outros 33 testemunhos, identificáveis graças a numerosos erros conjuntivos, dos quais apresento em seguida alguns exemplos significativos ${ }^{23}$ :

2) 6 a nobis $\omega$ nobis $\mathbf{v}:$ ut $\mathbf{B} A^{1} \mathbf{V}^{1}$ est $\mathbf{V}^{2}$ est ut $\mathbf{v}$ : videndum est $\omega$ videndum $\mathbf{v}$

Bruwaene, 1970, p. 41, propôs para o De natura deorum, situando $\mathbf{N}$ no mesmo nível de $\mathbf{T}$ («nous n'avons pas vu ce manuscrit», p. 38, n. 3) em um primeiro grupo de descendentes de V, distinto de uma "vulgate" não melhor definida (que imagino coincidir com os recentiores dos séculos XIV e XV) e de um terceiro grupo ao qual pertenceria $\mathbf{H}$ (sic!, cf. supra n. 9).

${ }^{20}$ Atribuíveis quase que exclusivamente à presença na Itália de Vat4, manuscrito fruto de uma intervenção de douta colação F-v, realizada por Poggio Bracciolini e perpetuada em seus apógrafos, que, pertencendo à família de $\mathbf{F}$, não são objeto deste artigo. Um caso distinto é $\mathbf{C h i s , ~ c o ́ p i a ~ d e ~}$ Vat4 até o $\$ 105$ e, daí em diante, copiado de algum descendente de V (cf. Malaspina et Al., 2014, p. 608-10); um outro caso é a segunda mão de Gadd (cf. infra § 4.3) e a segunda mão de Par6, que introduz lições provenientes de $\mathbf{F}$ num descendente de $\mathbf{V}$ através de Scor4 (cf. infra $§ 4.5$ ). Bem mais invasivas são as contaminações "internas" entre diferentes membros da família de $\mathbf{V}$, que tornam a localização estemática sempre mais difícil à medida que se distanciam do protótipo.

${ }^{21}$ Recordo que A não possui descendência, salvo por meio de $\mathbf{F}$, portanto, a coincidência de $\mathbf{A}^{2}$ com $\mathbf{V}^{2}$ é um fato isolado, sem consequências.

${ }^{22} \mathrm{Cf}$., no entanto, infra $\mathrm{n}^{\circ} 8$.

${ }^{23}$ Os exemplos chegam ao $\S 104$, onde, como se disse, termina o texto de $\mathbf{V}$ em nosso domínio. $\mathrm{Na}$ realidade, ainda na parte sucessiva, é possível distinguir, com alguma probabilidade, os erros nativos de $\mathbf{V}$ daqueles que derivam do seu primeiro apógrafo (cf. Malaspina, em preparação). 
: 7 cuperent $\omega$ cupere $\mathbf{v}: 11$ inquit iterum ante mecum $\mathbf{v}: 12$ qui sosus $\omega$ qui Solus $\mathbf{v}$ : et in $\omega$ ut in $\mathbf{v}:$ quae contra Platonem erat post praetermittenda est $\mathbf{v}$ : 15 diceret $\mathbf{B}^{\mathbf{2}} \mathbf{A}$ dicere $\mathbf{B}^{\mathbf{1}}$ om. $\mathbf{V}^{\mathbf{1}}$ cognosceret $\mathbf{V}^{\mathbf{2}}$ agnosceret $\mathbf{v}^{24}$ : 22 enim notitias $\omega$ notitias $\mathbf{v}: 26$ quid quod $\omega$ quod $\mathbf{v}: 28$ dicere percipi posse $\omega$ diceret posse percipi $\mathbf{v}: 29$ quae $\omega$ et que $\mathbf{v}: 30$ artificio $\omega$ artificioso $\mathbf{v}: 31$ corroborat $\omega$ et $\mathbf{v}: 32$ eius modi $\omega$ huius modi $\mathbf{v}$ : et hoc $\omega$ hoc $\mathbf{v}: 40$ si omni $\omega$ sed omni $\mathbf{v}: 43$ illa uera $\omega$ illa uero $\mathbf{v}: 49$ obiectum $\omega$ ab v : 50 et si $\omega$ ut si $\mathbf{V}^{2} \mathbf{F}^{2}$ et ut si $\mathbf{v}: 54$ plane esse $\omega$ esse plane $\mathbf{v}: 63$ quidem te $\omega$ te quidem $\mathbf{v}: 72$ ea dicimus $\omega$ dicimus ea $\mathbf{v}$ : 75 addissoluit $\mathbf{V}$ dissoluit $\mathbf{B}^{2} \mathbf{A}^{2} \mathbf{F}$ adis soluit $\mathbf{v}: 82$ quantus $\omega$ quantum $\mathbf{v}: 93$ quid plura $0 m . \mathbf{v}: 95$ aut falsum $\omega$ an falsum $\mathbf{v}: \operatorname{sint} \omega$ sunt $\mathbf{v}$ : 98 ludere AF cludere $\mathbf{B V S N} \mathbf{N}^{1} \mathbf{v}$ concludere $\mathbf{N}^{\mathbf{1}} \mathbf{v}$ : 100 si iam $\omega$ suam $\mathbf{v}$

Tal estado de fato leva a postular a existência de um apógrafo de $\mathbf{V}$, que chamamos $\mathbf{v}$, fonte comum do grupo, e, consequentemente, a indagar se ele coincide com algum dos 33 testemunhos ou se deve ser considerado perdido. A imensa maioria desses data dos séculos XIV-XV e é, portanto, excluída por óbvias razões cronológicas. Os mais antigos, afora Scor4 (séc. XIII), são T (XII-XIII) e $\mathbf{N}$ (séc. XII), os únicos anteriores ao século $\mathrm{XIII}^{25}$, portanto, os primeiros a possuírem indícios de ser o apógrafo de $\mathbf{V}$, do qual dependem os outros.

Todavia, $\mathbf{T}^{26}$ é, por sua vez, mutilado em quase metade da obra (contém somente os $§ \S 7-83$ ) e é, há algum tempo, considerado em todo o Corpus Leidense como uma cópia de $\mathbf{N}^{27}$, o que é fácil demonstrar também em relação ao Luc., com base na série de erros conjuntivos, que veremos em breve no $n^{\circ} 4$, e em menores coincidências paleográficas e ortográficas ${ }^{28}$. Ademais, uma série

${ }^{24} \mathrm{O}$ erro é provavelmente justificado por uma particularidade gráfica de $\mathbf{V}$, a saber, o sinal de referência $\Delta(110 \mathrm{v}$, I col., 7, reproduzido também 111r, II col., 18) em margem em frente a cognosceret, interpretado pelo copista sucessivo como $A$ de agnosceret.

${ }^{25}$ Eles não contêm o De legibus ou os Academici e, portanto, são excluídos dos estemas de Schmidt e Hunt.

${ }^{26} 126$ p., pergamináceo, duas colunas em escritura muito cuidada formalmente, mas plena de incorreções, sem intervenções de corretores; contém, de Cícero, Luc. (f. $1 \mathrm{r}-8 \mathrm{v}, \S 7$ sunt etiam - §83 ut minuam); De natura deorum I-III (com lacunas e inversões, f. 9r-26r); De fato (f. 26r-30v); Epistulae ad familiares (f. 31r-61v). A página com os $\S$ 1-7 do Luc. desprendeu-se, mas a outra metade desse último fólio do quínio é o atual fólio 9, que possui ao final um sinal de referência para a primeira palavra do quaterno sucessivo (controversiam), que, no entanto, desprendeu-se, fazendo desaparecer o final do Luc. e o início do De natura deorum até vere] amur esse non possit de nat. 1, 102, com o qual se inicia o atual fólio 10r. Na margem superior do fólio 1r, uma mão muito mais tardia acrescenta Majoris monasterii Congregat S. Mauri (abadia de Marmoutier).

${ }^{27}$ Com algumas exceções, cf. supra n. 19.

${ }^{28} \mathbf{T}$ conserva até mesmo os sinais de parágrafo de $\mathbf{N}$, como entre Hortensius e Cum ( 10 ), ou transforma-os em iniciais de cor azul, como Sequitur (§ 30), Nunc (§ 37); segue, em geral, $\mathbf{N}$ bem de perto nas particularidades gráficas, como heridictum ( $\$ 11)$ para heri dictum; o erro Nichil necesse est (§ 16) é o fruto de uma leitura errônea do Nichil neê de $\mathbf{N}$ (= Nibilne est); a ditografia de quae aut nulla sunt aut internosci a falsis non possunt no $§ 22$ corresponde a quase exatamente uma linha de $\mathbf{N}\left(2 \mathrm{v}\right.$ col. II). T foi copiado após a revisão de $\mathbf{N}^{2}$ (o que se vê 
de lectiones singulares atesta que $\mathbf{T}$ não tem relação com nenhum dos códices conhecidos do Luc. e se caracteriza, portanto, como último testemunho do "fim da linha" da tradição:

3)29 23 non possint $\omega$ possint $\mathbf{T}$ : quaerendi $\omega$ quendi $\mathbf{T}$ : tum inventa $\omega$ tamen inventa $\mathbf{T}: 27$ possit esse $\omega$ esse possit $\mathbf{T}: 28$ non possent $\omega$ non possint $\mathbf{T}$ : 29 haberet $\omega$ rent $\mathbf{T}$ : esse dicerent $\omega$ esse dicererent $\mathbf{T}: 30$ aliqua sic $\omega$ aliqua si $\mathbf{T}: 31$ et om. $\mathbf{T}: 33$ ullum habere $\omega$ nullum habere $\mathbf{T}: 34$ aut $\omega$ ut $\mathbf{T}: 35$ percipis sed $\mathbf{B}^{2} \mathbf{A}^{2} \mathbf{V}^{2} \mathbf{N}$ percipisset $\mathbf{B}^{1} \mathbf{A}^{1} \mathbf{V}^{1}$ perciperis sed $\mathbf{T}$ : quid eo $\omega$ qui eo $\mathbf{T}: 36$ interest $\omega$ est $\mathbf{T}$

Restar-nos-ia apenas $\mathbf{N}^{30}$ (que apresenta o Luc. sem maiores lacunas) para cobrir a função de v: ao menos esta é a vulgata no Corpus Leidense se se pensar que Plasberg o considerava apógrafo de $\mathbf{V}$ já corrigido por $\mathbf{V}^{231}$ e recorreu às suas lições a partir do $\S 104$ do $L u c$. em substituição a $\mathbf{V}$, enquanto anteriormente esse estava quase integralmente ausente do aparato, em rígida obediência à eliminatio codicum descriptorum. Van den Bruwaene, 1970, p. 37, foi além, afirmando que $\mathbf{N}$ "est copié incontestablement sur V, on peut donc refaire la tradition V grâce à N" (destaque meu). Não possuo argumentos para julgar a validade dessa afirmação a respeito do De natura deorum, a qual van den Bruwaene se referia, mas posso dizer que, a respeito do $L u c$., é incontestável que $\mathbf{N}$ não seja cópia direta de $\mathbf{V}$, mas do seu primeiro apógrafo $\mathbf{v}$, com o qual compartilha as lições conjuntivas supra $\mathrm{n}^{\circ} 2$, do qual, porém, distancia-se por uma série de erros que compartilha somente com T (nos §§ 7-83, nos quais a comparação é possível) e não com os demais 31 pertencentes à família. Dado o alto número de ocorrências, apresento em seguida uma seleção, também aqui limitada por alguns $\S \S(1-32)$ :

pelo hee do § 22), mas antes das posteriores intervenções de $\mathbf{N}^{3}$ (volebant, § 33); distingue-se de $\mathbf{N}$ corrigindo-lhe erros ortográficos banais como Antiboum (§ 11), Philioni (§ 11) e aliut ( 22), normalizando em -em o Socraten de N (§ 14) e as formas arcaizantes como percipiundi (§26); enfim, sente-se livre de não seguir $\mathbf{N}$ na escolha ortográfica de formas assimiladas ou etimológicas dos prevérbios.

${ }^{29}$ Em razão do grande número de exemplos disponíveis, limito-me aos §§ 23-36.

${ }^{30}$ Membranáceo, em duas colunas (como V e T), contém Luc. (1r-13r); De natura deorum (13r-46v); De fato (46v-50v); Epistulae ad familiares I-VIII (51r-91v); Historia Daretis de historia Troiae $(92 \mathrm{r}-97 \mathrm{v})$. Escrito por várias mãos, das quais a primeira possui traços mais agudos e goticizantes do que as sucessivas, não possui feituras de prestígio, se ressalvadas as capitulares retocadas em mínio apenas no fólio 1 . As margens atestam escassas glosas, além da atividade de um corretor $\left(\mathbf{N}^{2}\right)$ que recorre a um ponto ou a uma linha mais abaixo para expungir, acrescenta letras e palavras na entrelinha superior, usando uma vírgula entre as letras como sinal de referência, e colaciona com segurança o antígrafo de $\mathbf{N}$, sobretudo a fim de reintegrar as numerosas omissões, ponto débil da primeira mão.

${ }^{31}$ «In posteriore Luculli parte ad supplendum illius defectum adscivi codicem bibliothecae Parisinae [...]. Is ut multi recentiores fluxit e Vindobonensi iam priorum correctorum $\left(\mathbf{V}^{2}\right)$ curas passo" (Plasberg, p. xxi; cf., no entanto, infra n. 33). 
4) 1 ad om. $\mathbf{N}: 2$ in negotiis $\omega$ negotiis $\mathbf{N}: 3$ cum utilitate om. $\mathbf{N}: 13$ etiam om. NT : 15 congruentes $\omega$ congruens NT : 16 igitur actum $\omega$ actum igitur NT : 19 aut om. NT : multaque facimus usque eo dum aspectus ipse fidem faciat sui iudicii. quod idem fit in vocibus om. NT : requirat om. NT : 21 mortale $\omega$ rationale mortale NT : 23 modo om. NT : 24 Atque etiam illud perspicuum est, constitui necesse esse initium quod sapientia om. NT : 27 decretum nullum $\omega$ nullum decretum nullum NT : 32 docere om. NT

É, portanto, um primeiro resultado seguro da minha pesquisa que, em relação ao $L u c$., os recentiores pertencentes a esse ramo não descendem de $\mathbf{N}$, mas são, por assim dizer, primos, dependendo todos de um único apógrafo perdido de $\mathbf{V}$, a saber, $\mathbf{v}$, que devemos situar cronologicamente entre $\mathbf{V}$ e $\mathbf{N}$, entre os séculos IX e XII portanto. Mesmo não havendo provas seguras, é possível imaginar v como fruto do trabalho de revisão realizado sobre $\mathbf{V}$ ainda em pleno século IX por $\mathbf{V}^{2}$ (isto é, por Lupo e por sua escola) talvez em Ferrièrres ${ }^{32}$, em paralelo com o que fora feito sobre $\mathbf{B A}$ para o exemplar $\mathbf{F}$ em Corbie.

Uma consequência edótica imediata é que, para os $\S \S 104-48$, em que falta $\mathbf{V}$, seria mais correto apresentar em aparato como sucedâneas não as lições unicamente de $\mathbf{N}$, mas ao menos as de $\mathbf{v}$, constituído, como consta supra $\mathrm{n}^{\circ} 2$, pelo consensus dos seus apógrafos. Os erros peculiares de $\mathbf{N}$ continuam, de fato, ainda após o § 104: já que não são originários de $\mathbf{V}$ (se assim fossem, deveriam ser encontrados também em $\mathbf{v}$, e não só em $\mathbf{N}$ ), possuem valor probatório como disiunctivi de N. Eis alguns de seus erros, limitados por brevidade aos $§$ 133-48:

5) 133 illa $\mathbf{B} \mathbf{A}^{3}$ ille $\mathbf{A}^{\mathbf{1}}$ om. $\mathbf{N}$ : 134 qui cum $\omega$ cum qui $\mathbf{N}$ : 137 qui tum $\omega$ qui tum videbitur $\mathbf{N}: 145$ At scire negatis quemquam rem ullam nisi sapientem om. $\mathbf{N}: 146$ artificia $\omega$ artificiosa $\mathbf{N}^{33}$

\subsection{Os descendentes diretos de $v$}

Como já mencionado, os apógrafos de $\mathbf{v}$, incluídos NT, permitem-se catalogar, com bastante facilidade, em classes com base em erros conjuntivos e, sobretudo, em quatro lacunas maiores ( $\S \S 28,28,106,144)$, cujo acúmulo

32 Cf. Pellegrin, 1988, p. 139-40; Ricciardi, 2005, p. 62. Que V tenha sido copiado em Ferrières é um dado que parecia ter sido obtido ex auctoritate de B. Bischoff (cf. Schmidt, 1974, p. 168, e Rouse, 1983, p. 126), contudo, recentemente foram levantadas dúvidas sobre a existência de um scriptorium nessa sede (cf. von Büren, 2007, p. 173: devo esta incorporação bibliográfica a Michael Reeve).

${ }^{33}$ Veremos infra no $§ 7$, a quais recentiores é suficiente limitar-se a fim de reconstruir $\mathbf{v}$ e a parte faltante de $\mathbf{V}$, seguindo o princípio da eliminatio codicum descriptorum. Por amor da verdade, deve-se dizer que Plasberg, embora sem nunca explicitá-lo, devia ter-se dado conta da natureza de erros peculiares de muitas particularidades de $\mathbf{N}$ e, portanto, excluiu-as de seu aparato (tanto maior quanto minor), a partir de todas aquelas elencadas aqui como $\mathrm{n}^{\circ} 5$. 
sucessivo marca cada vez mais a distância dos recentiores do arquétipo.

Os descendentes diretos distinguem-se por exclusão, pois apresentam as numerosas perdas de uma ou duas palavras de $\mathbf{V}$ e somente a lacuna maior do $\S$ 144, omnes] qui in contione stabunt exules ser [vos insanos, que reencontraremos infra $\mathrm{n}^{\circ}$ 8: essa é comum a vm, portanto, mesmo encontrando-se na parte perdida do texto, é seguramente originária de $\mathbf{V}$ e não corrigida por $\mathbf{V}^{2}$. Tal estágio do texto é, todavia, atestado, na linha de $\mathbf{v}$, apenas em $\mathbf{N}$, em dois códices muito tardios, Par9 e Nicc (séc. XV), e nos apógrafos deste último, dos quais trataremos no parágrafo seguinte.

Par9, pergamenáceo, hoje reduzido aos fólios $79 \mathrm{r}-234 \mathrm{v}$, contém as Saturnálias, de Macróbio (79r-171v), o Luc. (175r-197r) e, após o fólio 198, faltante, o De divinatione (199r-234v); nele, não há glosas ou marginalia, mas traços de um corretor mais tardio, que intervém com traço cursivo e curto entre as linhas. A mão dos dois diálogos ciceronianos é a mesma, densa e plena de abreviaturas, muito diversa daquela que assina Macróbio em uma gótica de traço espesso. O copista foi identificado como Nicolas de Clamanges ou Clémanges ${ }^{34}$ por F. Gasparri, que enquadra a sua grafia como «pré-humanística italianizante». É possível vincular Par9 com Paris, Bibliothèque Nationale, lat. 15084 (indicado com S por Schmidt, 1974), que possui De legibus, De fato e o Fédão traduzido por Leonardo Bruni, cuja datação proposta é $1404-1405^{35}$.

Se Par9 atesta a presença de apógrafos de $\mathbf{v}$ na França no início do século $\mathrm{XV}$, Nicc atesta a sua passagem na região italiana central: em pergaminho e de pequenas dimensões, esse contém sete obras ciceronianas, dentre as quais três do Corpus Leidense, escritas por uma só mão em uma humanística bastante clara e equilibrada, ainda que pouco caligráfica e plena de abreviaturas ${ }^{36}$. Nos fólios de guarda iniciais, dentre as assinaturas numéricas de várias mãos, destaca-se

${ }^{34}$ Gasparri, 1994, tabela 64 (f. 217); suas características parecem-me o titulus ${ }^{\text {t' }}$ para -tur, a forma idêntica de $-a$ - e de - $c i$ - e a forte semelhança entre $c$ e $t$. Nicolas de Clamanges (circa 1360-1437) esteve ativo em Paris do ano 1423 ao 1437 e é lembrado também na tradição do Florilegium Angelicum (cf. Rouse; Rouse, 1976, p. 78, 81) e na do De legibus (cf. Schmidt, 1974, p. 432-3; Rouse, 1983, p. 127). Em seguida, Par9 entrou na Biblioteca do convento agostiniano de Saint Victor, em Paris, onde foi registrado no catálogo de Claude de Grandrue, do ano 1514 (cf. Vernet, 1989, I, p. 87, e Ouy, 1999, II, p. 529).

${ }^{35}$ Embora a grafia (gótica bastarda francesa) seja diversa, ambos pertenceram a Saint Victor e, talvez um pouco antes, a Nicolas de Clamanges (cf. Schmidt, 1974, p. 59, e Rouse, 1983, p. 127).

36145 x $214 \mathrm{~mm}$, com espaço de escritura de 98 x 164 mm e 31 linhas por página, contém Luc. (1r-27r), Timaeus - texto não inventariado nem no index do manuscrito (cf. n. seq.) nem no catálogo impresso dos códices de San Marco do ano 1768 -, In Vatinium, De provinciis consularibus, De haruspicum responso, Topica, Partitiones oratoriae. O texto de har. resp. deriva de Paris, Bibliothèque Nationale, lat. 7794 (Tours, séc. IX) por meio de um intermediário corrigido (Reeve, 1988, p. 121, n. 17). 
aquela de Niccolò Niccoli († 1437), que compila o índice ${ }^{37}$.

É inevitável que códices florentinos do século XV tenham nas margens ou na entrelinha variae lectiones, especialmente o Corpus Leidense, após o retorno de Poggio Bracciolini do concílio de Costanza com F e com a sua cópia Vat4 ${ }^{38}$ : não surpreende, portanto, que, diferentemente de Par9, Nicc mostre os sinais da intervenção frequente, seja de um corretor não muito mais tardio, que escreve com tinta mais escura e usa, com rigor, pontos de eliminação sob a letra e sinais de referência no alto para as integrações, seja de uma mão mais gótica nas margens, pelo traço sutil e incerto.

Par9 e Nicc apresentam todos os erros conjuntivos de $\mathbf{v}$ catalogados supra $\mathrm{n}^{\circ} 2^{39}$, enquanto não apresentam aqueles de níveis mais baixos da tradição que veremos infra $\mathrm{n}^{\circ}$ 7. Ademais, ambos possuem falhas e erros específicos, que garantem não haver relações entre eles ou outros manuscritos conservados além da origem comum em v e da descendência que Gadd tem de Nicc, do qual tratamos agora ${ }^{40}$.

\subsection{Um parêntese florentino: Gadd e os seus apógrafos}

Gadd é um códice já bem estudado por P. L. Schmidt ${ }^{41}$ : ao menos dessa vez, as conclusões válidas para o De legibus podem ser estendidas com poucas modificações e acrescentadas também ao Luc. Trata-se, de fato, de um manuscrito escrito em humanística cursiva por volta de $1440^{42}$, que foi utilizado como

${ }^{37}$ A identificação da mão deve-se a Reeve, 1984, p. 268, seguido por Gentile, 2000, p. 83, n. 11: In hoc codice continentur hae orationes / M. Tullii Ciceronis liber iii et iiii Academicorum / Idem In Vatinium testem oratio / Idem de provinciis consularibus oratio / Idem de haruspicum responsis in Clodium/Topicorum ad Trebatium iurisconsultum/Idem partitionum \$S(anct)i marci d(e) Flo(rentia) ordi(nis) p(atrum) p(rae)dicator(um). Uma outra mão acrescenta Ex hereditate Nicolaj de Nicolis florentini viri doctissimj.

${ }^{38}$ Cf. supra n. 20 e Malaspina et A1., 2014, p. 595. Niccoli, ademais, recebeu em sua biblioteca os códices de Coluccio Salutati por ocasião da morte deste (cf. De Robertis; Tanturli; Zamponi, 2008, p. 309): dentre esses, com o Luc., estava Magl, rico em conjecturas e variae lectiones (cf. Senore, 2017, n. 3, 13 e 14).

${ }^{39}$ Mas, no $§ 54$ (plane esse $\omega$ esse plane v), Nicc está com $\omega$ e é pontualmente assim seguido por seu apógrafo Gadd (cf. § seq.). Mais que de uma contaminação com F, creio que se trate de uma falha mecânica, do mesmo modo da ulterior inversão esse plane que se lê em Yal, cópia de Gadd.

${ }^{40}$ E.g. no $§ 9$, a respeito das duas soluções omnia e omnino da tradição (cf. supra n ${ }^{\circ}$ 1), Par9 mostra a varia lectio ainda reconhecível como tal, com o(mn)ia em linha e (vel) omnino em entrelinha, enquanto Nicc e, com ele, Gadd e os seus apógrafos integraram ao texto o sem sentido vel omnino omnia, lição distintiva do grupo; no § 28, Par9 conserva ainda o genuíno ut id ipsum, em oposição a ut ipsum de Nicc, de Gadd e dos seus apógrafos, e as outras soluções dos ramos inferiores do estema (id ipsum Matr ut non id ipsum $\operatorname{Par}^{2}$ Par7 Schl). No sentido contrário, no $\S 84$, Par9 acrescenta como erro singular a inversão certe potest videre ao erro conjuntivo Vvm Nicc Gadd videre c. p. a respeito da vera lectio de BA videri c. $p$.

${ }^{41}$ Schmidt, 1974, p. 319; 328-35; cf. também Hunt, 1998, p. 127-41.

${ }^{42}$ Cartáceo, de 28 linhas por página em uma só coluna, sem elementos de valor e com 
antígrafo-base para uma série de cópias in folio de grande valor da série com decorações em bianchi girari, produzidas por cerca de duas décadas por Vespasiano da Bisticci e hoje propagadas pelo mundo afora ${ }^{43}$. Dos oitos apógrafos que Schmidt distingue para o De legibus ${ }^{44}$, sete contêm também o Luc. (Ball Bon Corv Dresd1 Fes Laur3 Yal), e, a esses, acrescento Lond, que não tem o $D e$ legibus. Um exame meticuloso do grupo estaria fora dos limites deste artigo e, sobretudo, constituiria um progresso limitado para a tradição do Luc., a partir do momento em que todos os oito conservam as lições particulares de Gadd, com o acréscimo de suas óbvias falhas particulares, mescladas a uma presença de F Vat4, ora mais leve, ora mais maciça a ponto de ocultar intercaladamente as lições distintivas da família de $\mathbf{V}^{45}$.

Mais profícuo é, na verdade, dedicar-se ao antígrafo de Gadd, que, como já dissemos, para o Luc., deixa-se identificar sem dúvidas em Nicc, enquanto, para os Academici, o texto deriva de Florença, Biblioteca Medicea Laurenziana, Conventi Soppressi $131^{46}$ e, para o De legibus, de um descendente de um códice perdido de origem francesa, indicado por $p$, que reveremos no $\S$ seguinte $^{47}$. Gadd revela, portanto, o esforço em recuperar uma coleção filosófica ciceroniana coerente e a mais completa possível, na qual o Corpus Leidense vem a ser reconstruído por diversas fontes em seis de seus oito componentes originários (faltam Paradoxa e Topica).

O texto do Luc. em Gadd diferencia-se daquele dos Academici e do De legibus porque se apresenta ainda como um genuíno membro da classe de $\mathbf{v}$, com

amplas margens ocupadas por uma trintena de glosas ao todo para o Luc., contém De natura deorum, De divinatione, De fato, De legibus, Academici libri (até 178r, sem explicit; ff. 178v-180v vazios), Luc. (chamado Acad. III et IV, 181r-211v), Timaeus e Somnium Scipionis. "Aquis pluvialibus valde maculatus» (Bandini, 1774, III, p. 662), pertence como n 26 aos códices com nota de posse «bernardi de puccinis» (f. 1r), que entraram na Biblioteca Laurenziana no séc. XVI (cf. Oakley, 2016, n²7).

${ }^{43}$ Sobre Vespasiano é obrigatória a referência de la Mare, 1996.

${ }^{44}$ Todos copiados diretamente de Gadd, sem passagens intermediárias, cf. Schmidt, 1974, p. 319-28, e também Malaspina, 2011, p. 553.

${ }^{45}$ É o caso de Corv, o único em relação ao qual se pode falar de uma contaminação sistemática das duas tradições, ao menos para o Luc. (cf. em geral Schmidt, 1974, 324-6 e Hunt, 1998, p. 134-5, que assinala o manuscrito como Pier). Um exemplo para todos está no $\S 135$, no nec ferri de $\mathbf{v}$ Nicc Gadd ${ }^{1}$, corrigido justamente em efferri por $\mathbf{G a d d}^{2}$ sobre os rastros de Vat4 (ecferri BA) e tornado haec efferri em Bon Corv Fes, como parte da tradição de $\mathbf{F}$ estranha a Vat4.

${ }^{46}$ Cf. Hunt, 1998, p. 60-1.

${ }^{47}$ Cf. Schmidt, 1974, p. 329: «[...] scheint die Hypothese erlaubt, in der vom Gaddianus benutzten $p$-Vorlage jenes auch dem Bodleianus vorliegende, direkt nach Frankreich weisende Exemplar zu sehen»; com Bodleianus entende-se Oxford, Bodleian Library, Auct. F.1.12, ao qual é alinhado como terceiro descendente, com Gadd, do mesmo apógrafo de $p$, também Wolfenbüttel, Herzog August Bibliothek, Aug.22.6.4 (3260), restrito como os precedentes do Luc. (cf. Schmidt, 1974, p. 206, que não atribui nenhuma sigla a esse testemunho intermediário). 
traços de contaminação por F, nem sempre via Vat4, os quais são, todavia, bem reconhecíveis, como correções interlineares ou variae lectiones marginais, antes de confundirem-se no texto dos vários apógrafos ${ }^{48}$. Referimos aqui alguns erros distintivos de Nicc Gadd, para acrescentar àqueles referidos supra n. 40, com a advertência de que, como se disse antes, nem sempre eles se mantêm em todos os apógrafos:

6) 22 aliquid $\mathbf{B A m}{ }^{49}$ aliquo v Par9 aliq ${ }^{\text {od }}$ Nicc aliquod Gadd : 106 etiam $\omega$ Par9 sed etiam Nicc Gadd : 134 nisi alterutrum sit $\omega$ ne si alterum nisi Par9 si ne si alteruter nisi Nicc ${ }^{1}$ si alteruter nisi Nicc ${ }^{1 c}$ Gadd Bon Corv Laur3 ne si alteruter nisi $\mathbf{N}$ Nicc $^{3}$ : 145 fecerat $\omega$ Par9 fecerit Nicc Gadd

Nem todas as particularidades de Gadd descendem de Nicc ou das interpolações de Gadd: em certos casos, encontra-se o erro nativo do copista, como no $\S 70$ umbra por umbram e no $\S 71$ ceteris por ceteri, erros transmitidos aos apógrafos ${ }^{50}$.

\subsection{O códice $\mathrm{x}$ e Matr}

O estágio sucessivo do texto do Luc. é de longe o menos atestado nos manuscritos que chegaram até nós e deriva de um testemunho perdido, o qual chamamos $\mathbf{x}$ : esse localiza-se entre $\mathbf{v}^{51}$ e a classe sucessiva (que tem início no séc. XIII), provavelmente ainda na França, e é caracterizada pelo saut du même au même do § 28 consentaneum esse] unum tamen illud dicere percipi posse consentaneum

${ }^{48}$ O Conventi Soppressi 131 dos Academici e o antígrafo perdido do De legibus, ao contrário, eram já fruto de uma contaminação de dois ramos diversos, a que se acrescentou, no momento da cópia de Gadd, aquela proveniente de Vat4 (por sua vez, contaminado, como sabemos, cf. supra n. 20 e Schmidt, 1974, p. 328: «[...] wie in den beiden Quellen, so auch hier [= Gadd] erneut zwei Textfassungen gemischt worden sind»). Todavia, a descrição que o próprio Schmidt, 1974, p. 328-9, faz do aspecto de Gadd é adequada também à seção do Luc.: «[...] das p-Exemplar zur Grundlage genommen wird; seine Eigenheiten treten im Fall von Doppelfassungen immer im Text auf. Mit der Poggio-Kopie [= Vat4] werden weniger überzeugende $p$-Lesungen beseitigt, sofern aber in Alternativfas|sungen die Wahl offen bleibt, rücken ihre Varianten interlinear oder marginal stets an die zweite Stelle». Basta um par de exemplos: no $§ 88$, eum somniare de $\mathbf{B} \mathbf{A V} \mathbf{V}^{\mathbf{1}} \mathbf{F}$ Vat4 é intervenção de $\mathbf{G a d d}^{2}$, retomado por parte dos apógrafos, como Yal, enquanto Lond mantém-se fiel ao eum somnia que Gadd ${ }^{1}$ deriva de $\mathbf{V}^{2} \mathbf{v} \mathbf{m}$; no $\S 134$, Gadd ${ }^{1}$ segue $\mathbf{v}$ na forma senseat (censeat $\mathbf{B}^{2} \mathbf{A}^{2} \mathbf{F}$ ), corrigida em entrelinha em sentiat, que provém de parte da tradição de $\mathbf{F}$ (mas não de Vat4, censet) e que se encontra isoladamente nos apógrafos de Gadd; no $§ 145$, o est etiam de $\mathbf{v} \mathbf{G a d d}^{1}$ é corrigido com expunção de est por $\mathbf{G a d d}^{2}$, cuja lição se transmite aos apógrafos.

${ }^{49}$ Cf. infra n. 63.

${ }^{50}$ Aqui, talvez a grafia particular cet $i$ de Nicc (mas também de Par9!) poderia justificar o deslize de Gadd, como o $§ 145$, onde digitos de Gadd $^{1}$ por -tis poderia provir de uma leitura desatenta de Nicc, cujo - $i$ - unido a um $-\int$ se assemelha a um -o-; nesse caso, contudo, o erro é corrigido por $\mathbf{G a d d}^{\mathbf{1 c}}$ e não se transmite aos apógrafos.

${ }^{51}$ Portanto, talvez já a partir do séc. IX-X, cf. supra n. 32 . 
esse [ut alia non possent, que se junta à lacuna do § 144 .

Tal estágio é conservado em um único códice, $\mathbf{M a t r}^{52}$, que já só pela sua datação do fim do século XIV e início do XV se localiza cronologicamente não só após $\mathbf{x}$, mas também após Scor4 protótipo da classe sucessiva. Ademais, o texto é particularmente impreciso, com omissões, falhas e incompreensões maiores em grande quantidade ${ }^{53}$, o que é necessário atribuir aos últimos copistas e não a $\mathbf{x}$, cujo texto não se deixa, portanto, reconstruir com facilidade ${ }^{54}$.

Noto, enfim, que, com x e Matr, a tradição do Luc. torna a distanciar-se daquela do De legibus: o antígrafo de Matr por esse tratado vem, de fato, indicado no mesmo $p$ que já conhecemos e ao qual ainda voltaremos. Esse é, para Schmidt, um ponto crucial do De legibus, pois dele derivariam, além de Matr, dois manuscritos ingleses atualmente desaparecidos (Fabricianus e Regius), o antígrafo comum de Gadd e de outros dois testemunhos e, por meio de um quinto apógrafo, toda a tradição recentior restante de $\mathbf{V}^{55}$, enquanto, para o $L u c$., $\mathbf{x}$ vem situado num nível menos alto da tradição.

\subsection{Scor4 e a classe $\varepsilon$}

Encaminhamo-nos para o final do exame de $\mathbf{v}$, com os últimos dois grupos, o primeiro dos quais, nascido na Itália, caracteriza-se pela inserção, no § 106, da terceira lacuna maior, igualmente causada por um saut du même au même: quisque meminit] habet ea conprensa atque percepta; falsi autem conprendi nibil potest; et omnia meminit [Seiron. A respeito das fases precedentes referentes a $\mathbf{v}$ e $\mathbf{x}$, são notáveis os vínculos internos entre os vários testemunhos da classe e, sobretudo,

\footnotetext{
${ }^{52}$ Pergamenáceo, de 203 fólios, contém Philippicae (extratos de mão diversa e mais recente), Timaeus, De fato, De legibus; Luc. (100v-122v), De divinatione, De natura deorum e é escrito em uma gótica bolonhesa que Schmidt, 1974, p. 205, atribui à França meridional. Dele pode-se reconstruir a atribuição ao Duque de Uceda, antes da passagem pela biblioteca de Filippo V no século XVIII e, enfim, pela Biblioteca Nacional (cf. de Andrés Martínez, 1988, s.v.). Matr possui elementos de valor, como belas miniaturas das iniciais, sobre fundo ouro (para o Luc. $100 v$ ), títulos contínuos na margem superior (em relação ao Luc., Introductorius luculli no verso e loquentis ad hortensios [sic, como no explicit] no recto), notas marginais, com os nomes dos personagens citados, e, enfim, raras correções interlineares de uma mão de traço mais sutil, que usa para as integrações o sinal de referência >.

53 Poucos exemplos de lectiones singulares dos $\$ \S$ iniciais do Luc.: $\S 2$ incredulis por incredibilis; verborumque por verborum; $\$ 3 \mathrm{om}$. cum; $\$ 4$ que por cum; totum por secum; $§ 5 \mathrm{om}$. etiam; om. Graecarum; om. ullum.

${ }^{54}$ Cf. e.g. o $§ 41$, em que o originário ea percipi non, já submetido a uma primeira inversão (ea non percipi Par9 Nicc Gadd), sofre uma segunda inversão em $\varepsilon$ (percipi ea non), que deve ser sucessiva a $\mathbf{x}$, mas a lição parcial de Matr (ea percipi) mostra uma corrupção independente, de cujo ordo verborum se consegue, de qualquer modo, deduzir que o texto de $\mathbf{x}$ devia estar com $\mathbf{V}$ em oposição a $\varepsilon$.

${ }^{55}$ Cf. Schmidt, 1974, p. 206-16; para o antígrafo de Gadd cf. supra n. 47; para Fabricianus e Regius, infra n. 92.
} 
desse é notável o protótipo, Scor4 ${ }^{56}$. A suas características gráficas devem-se alguns erros ${ }^{57}$ presentes seja em seus nove apógrafos (Gud Mag1 Par Par4 Par5 Par6 Par7 Schl Trec), que formam uma classe que chamamos $\varepsilon$, seja na última fase que dela depende, $\zeta$. Deles trazemos alguns exemplos, dentre aqueles identificados com riqueza por Senore, 2017, com a advertência de que contaminações internas e erros peculiares marcam todos esses testemunhos segundo as características típicas dos recentiores situados ao fundo dos stemmata:

7) 14 esse omnia $\omega$ omnia esse $\varepsilon \zeta: 17$ uero $\mathbf{B A}$ verum $\mathbf{V v}$ verum vere $\mathbf{M a t r}$ miru verum $S c o r 5$ verum enim $\varepsilon: 31$ animal om. $\varepsilon \zeta: 37$ nam cum uim quae $\mathbf{B}^{2} \mathbf{A}^{2} \mathbf{F}$ Nam cumque $\mathbf{V}^{1} \mathbf{v}$ Nam cumquae $\mathbf{V}^{2} \mathbf{v}$ Nam cum $\varepsilon \zeta$ : 45 progrediamur $\omega$ progrediatur $\varepsilon \zeta: 76$ sentire om. $\varepsilon \zeta: 103$ quod multa falsa probabilia $\omega$ probabilia quod multa falsa $\varepsilon \zeta$ : sonum nullum $\omega$ nullum sonum $\varepsilon \zeta: 113$ primum $\omega$ primo $\varepsilon \zeta: 115$ Non me $\omega$ Non ne me $\varepsilon \zeta: 129$ et idem $\omega$ et idem et $\varepsilon \zeta: 133$ dicebas $\omega$ dicebat $\varepsilon \zeta$

Mais uma vez, a reconstrução estemática do Luc. não coincide com a do De legibus, não só porque, nessa última, Scor4 é um apógrafo sem descendência de uma cópia de $p$, mas, sobretudo, porque Gud e o conhecido Trec (com notas marginais de Petrarca), que Schmidt considera pertencer a uma família w, distinta de $\mathbf{V}$, demonstram-se para o $L u c$. testemunhos secundários do ramo e cópias indiretas de Scor4 ${ }^{58}$.

\subsection{O último estágio, a classe $\zeta$}

Sem que se possa definir neste artigo qual dentre os testemunhos de $\varepsilon$ em nosso domínio seja sua fonte, tampouco quais sejam os vínculos internos, a última fase da descendência de $\mathbf{V}$, que, como se disse, indicamos com $\zeta$, estende-se entre os séculos XIV e, sobretudo, XV, em área prevalentemente italiana, por

${ }^{56}$ Graças a Senore, 2017. Scor4, pergamenáceo, de 240 fólios (267 x $\left.180 \mathrm{~mm}\right)$, conserva, escritos por várias mãos góticas em duas colunas, Luc. (1r-21f), De natura deorum, Tusculanae, Timaeus, De legibus, De finibus, De divinatione, De fato, Pro Marcello, Pro rege Deiotaro, Pro Ligario, Catilinariae e Philippicae nos fólios 1-228, seguidos por De anima e De fato de Alexandre de Afrodísia em uma tradução anônima. Originário da Itália norte-oriental (Verona?), esteve em poder de Antonio Agustín, arcebispo de Tarragona (Antolín, 1916, v. 4, p. 181-3), e antes, talvez, de Bernardino Maffei (1514-1553, cf. Schmidt, 1974, 231): a sua datação, entre os extremos da segunda metade do século XIV (Schmidt, 1974, 231) e do século XIII (Ántolín, 1916, v. 4, p. 181), é situada de modo persuasivo em pleno século XIII por Senore, 2017, p. 186-8.

${ }^{57}$ Limito-me a referir aquilo que Senore, 2017, p. 161-2, define como um «caso de manual», a saber, no $\S 138$, a frase vacemus omni molestia, que, em toda a tradição tardia (seja $\varepsilon$ ou os manuscritos do $\S$ seguinte), se apresenta como vacemus id est careamus omni molestia (com alterações mecânicas em alguns testemunhos). Apenas Scor4 (f. 20r col. I, r. 20) traz o texto genuíno, todavia, com a margem id est careamus, uma glosa que o resto da tradição engloba no texto.

${ }^{58}$ Cf. Schmidt, 1974, p. 177-85, e Senore, 2017, p. 186-7. 
meio de nove manuscritos identificados: Glas Harl Mon2 Neap Neap2 Ott Par8 Parm Pat. A característica que têm em comum é que, no atormentado $\S$ 28 , à lacuna indicada supra 4.4., acrescenta-se uma segunda, algumas palavras antes, sempre por saut du même au même: posse percipi]. Sed Antipatro hoc idem postulanti, cum diceret ei qui adfirmaret nibil posse percipi [consentaneum esse.

A tipologia dos manuscritos, amiúde de pequeno formato, é muito variada: vai desde exemplares de valor, como o pequeno Parm, com decorações em bianchi girari, até cópias cursivas, como $\mathbf{O t t}$, com numerosas correções e notas marginais. Esse último é ainda o único a ser estudado, ao menos superficialmente, para o Luc. ${ }^{59}$, mas o exame das lições de $\zeta$ não é mais de utilidade nenhuma para o estudioso do texto e da tradição manuscrita do tratado ciceroniano.

\section{Bert, Cant2 e William de Malmesbury}

Restam-nos apenas dois manuscritos descendentes de $\mathbf{V}$ que não pertencem à classe de $\mathbf{v}$, isto é, Bert e Cant 2 . A sua colocação estemática é definida pelo compartilhamento com $\mathbf{V} / \mathbf{V}^{2} \mathbf{v}$ das lições de que falamos acima na seção 1, mas, quando $\mathbf{v}$ se distingue de $\mathbf{V} / \mathbf{V}^{2}$, $\mathbf{m}$ não se distancia desse último: de fato, nas lições referidas supra $\mathrm{n}^{\circ} 2, \mathbf{m}$ está sempre com $\omega$. No que diz respeito ao estema, portanto, $\mathbf{m}$ dá origem a um ramo paralelo a $\mathbf{v}$ e desse independente, mesmo condividindo a descendência de $\mathbf{V} / \mathbf{V}^{2}$.

Muito comuns são os erros conjuntivos, que, como se disse, isolam $\mathbf{m}$ de todo o resto da tradição, e que apresento aqui em número reduzido:

8) 1 continuo $\omega \mathbf{v}$ continuoque $\mathbf{m}:$ admirarentur $\omega \mathbf{v}$ multi admirarentur $\mathbf{m}: 2$ Graeciae principem ponimus $\omega \mathbf{v}$ principem grecie ponimus $\mathbf{m}:$ in animo res insculptas $\omega \mathbf{v}$ insculptas in animo res $\mathbf{m}: 3$ ille rex $\omega \mathbf{v}$ rex ille $\mathbf{m}: 4$ Graecis litteris $\omega \mathbf{v}$ litteris grecis $\mathbf{m}$ : studio $\omega \mathbf{v}$ studio litterarum $\mathbf{m}: 5$ nec litterarum Graecarum nec philosophiae $\omega \mathbf{v}$ nec philosophie nec litterarum grecarum $\mathbf{m}$ : 7 disputent $\omega \mathbf{v}$ disputant $\mathbf{m}: 28$ est natum $\omega \mathbf{v}$ natum est $\mathbf{m}:$ perceptum a sapiente $\omega \mathbf{v}$ a sapiente perceptum $\mathbf{m}: 35$ is usu $\mathbf{B}^{2} \mathbf{A} ? \mathbf{F}$ his/hiis usu $\mathbf{V v}$ usu $\mathbf{m}$ : 38 perspicuam non adprobare om. $\mathbf{V v}$ appetere $\mathbf{m}: 50$ et si lupi $\mathbf{B} \mathbf{A} \mathbf{V}^{1} \mathbf{F}^{\mathbf{1}}$ ut si lupi $\mathbf{V}^{2} \mathbf{F}^{2}$ et ut si lupi $\mathbf{v}$ ut si lupi sint $\mathbf{m}$ : 62 sublata enim $\mathbf{B A}$ sublatenter $\mathbf{V} \mathbf{v}$ sic latenter $\mathbf{m}: 89$ adsunt $\mathbf{A} \mathbf{V}^{1}$ adsum (vel assum) $\mathbf{V}^{2} \mathbf{v}$ adversum $\mathbf{m}: 97$ dialectici pugnent $\omega \mathbf{v}$ pugnent dialectici $\mathbf{m}: 100$ consilia capiet $\mathbf{B A}$ consilia $\mathbf{V v}$ sumet consilia $\mathbf{m}: 102$ est perspicuum $\omega \mathbf{v}$ perspicuum est $\mathbf{m}: 104$ ut sequens probabilitatem $\omega \mathbf{v}$ ut sequatur probabilitatem $\mathbf{m}$ : aut occurrat $\omega \mathbf{v}$ occurrat $\mathbf{m}$ : aut etiam $\omega \mathbf{v}$ etiam $\mathbf{m}$ : non respondere $\omega \mathbf{v}$ respondere non $\mathbf{m} 106^{60}$ percipimus $\mathbf{B A v}$ percepimus $\mathbf{v}$ percipitur $\mathbf{m}$ : perceptarum $\mathbf{B A v}$ conceptarum $\mathbf{m}$ : licet $\mathbf{B A v}$ lucet $\mathbf{m}$ : aut concedendum $\mathbf{B A v}$ concedendum $\mathbf{m}$ : et facere $\mathbf{B}^{\mathbf{1}} \mathbf{A}^{1} \mathbf{v}$ et facile

\footnotetext{
${ }^{59}$ Malaspina et A1., 2014, p. 612-4.

${ }^{60}$ Recordo que, a partir do $\S 104$, não podemos mais confiar em V.
} 
$\mathbf{B}^{2} \mathbf{A}^{2} \mathbf{F}$ facere $\mathbf{m}$ : 111 illam $\mathbf{B A v}$ illa $\mathbf{m}$ : 135 consentiunt $\mathbf{B A v}$ dissentiunt $\mathbf{m}$ : pro veris $\mathbf{B A v}$ pro nobis $\mathbf{m}$ : 144 undique omnes $\mathbf{B A v}$ omnes undique $\mathbf{m}$ : quod eos omnes qui in contione stabunt exules servos insanos esse dicatis $\mathbf{B A}$ quo deos omnes vos insanos esse dicatis $\mathbf{v}$ quod eos omnes vos insanos esse dicatis $\mathbf{v}$ quo deos omnes insanos esse dicatis $\mathbf{m}^{61}$

Enfim, Bert e Cant2 possuem, cada um, um número não elevado de lições peculiares, sobretudo falhas e erros mecânicos, que podem ser imputados provavelmente aos copistas finais do século XV. Deles apresento, em seguida, alguns exemplos, relativos, primeiro, aos erros peculiares de Bert, depois, relativos a Cant2, e, enfim, a alguns dos casos em que os dois manuscritos operam de maneira independente:

9) 3 in eodem $\omega \mathbf{v}$ Cant2 in eo Bert : 5 Catonem $\omega \mathbf{v}$ Cant2 Cathonem Bert : 44 rebus $\omega \mathbf{v}$ Cant2 in rebus Bert : 106 conprendi BAv Cant2 apprehendi Bert : 111 Ne illam BAv Ne illa Cant2 De illa Bert : 144 occludi BAv Cant2 concludi Bert

6 ad populares $\omega \mathbf{v}$ Bert in populares Cant2 : 14 similiter Cant2 simile $\omega \mathbf{v}$ Bert : 35 ex hoc illud $\omega \mathbf{v}$ Bert ex hoc Cant 2: 85 nec admodum $\omega \mathbf{v}$ Bert set nec admodum Cant2

3 mithridatico $\omega \mathbf{v}$ mitridatico $\mathbf{B}^{1} \mathbf{v}$ Cant 2 mitdatico Bert : 4 antiochus A Anthiocus $\mathbf{B}^{2} \mathbf{v}$ Bert Anthiochus $\mathbf{F}$ Cant2 : 102 sed scriptum est ita $\omega \mathbf{v}$ scriptum est (ergo) ita Bert scriptum est igitur ita Cant2 : 104 possit NF ${ }^{3}$ Bert posset BAF $^{1}$ Cant2

Tais lições parecem garantir que nem Bert é apógrafo de Cant2 nem Cant2 apógrafo de Bert: delineia-se, portanto, o quadro de um manuscrito descendente de $\mathbf{V}$ por via distinta de $\mathbf{v}$ e sobre o qual foram copiados dois apógrafos, provavelmente diretos. Se forem examinadas, então, as lições conjuntivas, nota-se logo que poucos erros podem ser apurados como corrupções mecânicas: algumas intervenções são motivadas gramaticalmente, mesmo que erradas, e estão presentes em modo paralelo e independente também em parte da descendência de $\mathbf{v}^{62}$; outras, do mesmo teor, são acertadas ${ }^{63}$. Que nesse caso não se trata de fruto da colação de $\mathbf{B A}$ ou de alguns de seus descendentes parece poder-se deduzir do fato de que mais frequentemente $\mathbf{m}$ conjectura ope ingenii, demonstrando plena

${ }^{61}$ Cf. supra $\S 4.2$.

${ }^{62}$ E.g. 3 instrumento BA instrumenti VN Nicc Par9 ${ }^{1}$ instrumentis $\mathbf{m}$ Gadd Par9 ${ }^{1 \mathbf{c}}$.

${ }^{63}$ E.g. no $\S 1$, o absurdo peraccepta de $\mathbf{V v}$ é por $\mathbf{m}$ reconduzido ao correto percepta de BA com uma intervenção bastante simples realizada em ordem esparsa também por alguns copistas e corretores de v (Corv ${ }^{2}$ Magl Neap Pat Yal); no § 20, a correção do cernet de Vv volta ao subjuntivo cernat testemunhado por $\mathbf{B A}$; no $§ 22$, aliquo de $\mathbf{V v}$ é corrigido em aliquid, lição de $\mathbf{B A}$; no $\S 139$, parece-me casual a coincidência com $\mathbf{F}^{3}$ na conjectura laboro ut $\mathbf{B}^{2} \mathbf{A}^{2} \mathbf{F}^{3} \mathbf{m}$ por labore ut $\mathbf{B}^{\mathbf{1}} \mathbf{A}^{1} \mathbf{S} \mathbf{N F}^{\mathbf{1}} \mathbf{v}$. 
inteligência do texto, mas afastando-se inevitavelmente da recta lectio de BA. Dentre os exemplos supra $\mathrm{n}^{\circ} 8$, coloco em evidência a significativa lacuna de perspicuam non adprobare (§38), não reconhecida por $\mathbf{V}^{2}$ e continuada em $\mathbf{v}$ sem, a meu ver, tentativas de emendas. Em $\mathbf{m}$, por sua vez, em seu lugar lê-se appetere, com que ao menos o sentido gramatical é preservado ${ }^{64}$. Paralelos os casos do $\S 62$, onde sublata enim de $\mathbf{B A}$, corrompido na vox nibili de $\mathbf{V v}$ sublatenter, é manipulado em sic latenter por $\mathbf{m}$; do $\S 89$, onde adsunt, me expetunt, já corrompido por $\mathbf{V}^{2}$ em adsum /me (e tornado amiúde assume em $\mathbf{v}$ ), é reelaborado em adversum me expetunt; enfim, do $\$ 100$, onde a perda de capiet depois de consilia em $\mathbf{V}$ (cf. supra $\mathrm{nn}^{\circ} 1$ e 8) é restaurada por $\mathbf{m}$ pelo sentido, integrando sumet antes de consilia. Enfim, que mais modificações se concentrem às vezes em poucas linhas de texto faz imaginar a tentativa de uma releitura global de períodos particularmente hostis ${ }^{65}$. Somente a Cant 2 deve-se ao menos uma correção segura do texto, o similiter do $\S 14$, até agora atribuído no aparato Plasberg a "dett VenII" ${ }^{6}$. Frente a um modus operandi tão sistematicamente intrusivo e corajosamente conjectural, é possível pensar que até mesmo as numerosas inversões de $\mathbf{m}$, presentes supra $\mathrm{n}^{\circ} 8$, não sejam, como ocorre amiúde, falhas inconscientes, mas deliberadas adaptações a um cursus ou a um ordo verborum considerado mais correto ou elegante ${ }^{67}$.

Mas quais características possui e como e onde se formou $\mathbf{m}$, cuja existência permaneceu até agora ignorada? Proponho que, para responder de modo exauriente a essa indagação, seria necessário um estudo de Bert Cant 2 sistemático, isto é, relativo também a outros tratados ciceronianos então conservados ou ao menos àqueles do Corpus Leidense, estudo que, porém, por evidentes razões, não pode ser conduzido neste artigo, em que me limito a reportar as informações notáveis sobre a história dos dois códices e a trazer algumas conclusões e algumas conjecturas válidas para o $L u c$, reservando-me aprofundar o assunto tal como merece em outro momento.

${ }^{64} \mathrm{O}$ período soa assim em m: quo modo non potest animal ullum non adpetere id quod adcommodatum ad naturam adpareat, sic non potest obiectam rem appetere.

${ }^{65}$ Enquanto um tanto improvisado é o trabalho de correção do $\S 35$, que, em $\omega$, resulta quid illud [illa edd.] in quibus consentiunt num pro veris probare possumus $\mathrm{e}, \mathrm{em} \mathbf{m}$, quid illud in quibus dissentiunt num pro nobis probare possumus, mais elaborado é o $\$ 104$, que soa assim na ed. Plasberg: id cum ita sit, alterum placere ut numquam adsentiatur, alterum tenere ut sequens probabilitatem, ubicumque haec aut occurrat aut deficiat, aut "etiam" aut "non" respondere possit, e, assim, transforma-se em m: ...ut sequatur probabilitatem, ubicumque baec occurrat aut deficiat, $\underline{\text { t }}$ etiam respondere non possit/posset.

${ }_{66}$ A sigla refere-se à edição de Veneza de 1494/96; os códices deteriores são mais bem detalhados pela edição de Davisius, 1725, ad loc., p. 70-1, que lia similiter nos seus manuscritos indicados por Paris. 2 e Paris. 4, além de nosso manuscrito de Cambridge. Mas nenhum dos parisienses hoje consultáveis possui similiter (voltaremos a esta conjectura no fim deste §). 86).

${ }^{67}$ Sobre o tema, refiro o sempre fundamental Ronconi, 1934 e Kaster, 2016 (cf. infra n. 
Entre os dois exemplares, o mais conhecido é certamente $\mathbf{C a n t} \mathbf{2}^{68}$, datado de 1444 e já há tempos reconhecido como apógrafo tardio de um manuscrito que pertencera a William de Malmesbury (circa 1090-1143), monge conhecido por seus volumes sobre a história da Inglaterra bárbara e por suas incalculáveis leituras, dentre as quais grande espaço era dedicado às ciceronianas ${ }^{69}$. Como ocorre amiúde com os fatos textuais que suscitam curiosidades distintas ao filólogo clássico e ao medievalista, as pesquisas sobre Cant 2 seguiram às vezes percursos independentes: os estudiosos do Corpus Leidense haviam assinalado, já no século XIX, a presença de uma subscriptio e de numerosas notas que remontavam a William, embora com ideias ainda vagas sobre a origem do manuscrito ${ }^{70}$. Dentre as notas, uma em particular concerne ao Luc. e aos Academici, e mostra que William, referindo passagens tanto do proêmio do De divinatione quanto de Santo Agostinho, tinha buscado reconstruir uma estrutura em quatro livros do tratado, chegando a uma personalíssima interpretação: o livro I era, para ele, constituído por aquele que hoje é, para nós, o Varro (cuja existência William conhecia, embora não o tivesse lido, por não ter encontrado nenhuma cópia na Grã-Bretanha); o livro II, do perdido Catulus, enquanto o Luc. teria composto os livros finais III

${ }^{68}$ Pergamenáceo, de ii +309 fólios, em duas colunas de 47 linhas, escritas por uma mão gótica caligráfica muito equilibrada e de fácil leitura, a que se devem também as frequentes notas marginais (nomes próprios, títulos recapitulativos, mas ainda mais elaboradas notas de comentário exegético e filosófico, como veremos). Cant 2 contém: De senectute, De natura deorum, De divinatione, De fato, extraídos dos livros V e VI do De civitate Dei de Santo Agostinho, relativos aos Academici libri (92r-v); o Luc. (93r-111v); notas de comentários ao Luc. de William de Malmesbury (ego Will'm' Malmesburgensis, 112v, col. I) com retomadas do De divinatione e de Santo Agostinho (111v-112v), Timaeus e Paradoxa; seguem do fólio 12313 discursos ciceronianos (para muitos dos quais Cant2, chamado $K$ nos aparatos, desempenha um papel não secundário, cf. Reeve; Rouse, 1983, p. 80-1); as invectivas de Salústio In Ciceronem e do Pseudo-Cícero In Sallustium; Philippicae; De officiis e, enfim, as Tusculanae. Uma numeração mais antiga (para o Luc. 88r-106v, a única nota a AA.VV., 1867, p. 507) aparece em cima, à direita, riscada e substituída por uma mais correta. Deviam ser elementos de valor as iniciais miniadas, que, porém, foram recortadas do pergaminho, com consequente perda de texto no recto e no verso dos fólios 93 (incipit do "livro I") e 101 (incipit do "livro II", cf. infra nn. 71 e 80).

${ }_{69}$ Para a sua bibliografia, limito-me a referir Thomson, 2003, Malaspina, 2015, p. 33-5, e o recente Thomson, 2017, muito atentos também ao dado codicológico; sobre as suas leituras p. 40-75.

${ }^{70}$ Veja-se a edição do De divinatione, de Pease, 1920, p. 611, que retoma a mais longa nota de Reid, 1885, 66-68: «A subscription [no fim do manuscrito] reads: per manus Theodorici Nycolai Werken de Abbenbroeck (in S. Holland) liber explicit anno domini 1444. The writer was, then, a Hollander; but he seems to have written in England [afirmação hoje não mais sustentável, cf. infra]. The MS was given to the library by Archbishop Rotherham about four centuries ago. On the margin are many notes ascribed to Malmesbury (died ca. 1142), nearly all in the first person, so that it appears that this MS is derived from one annotated by William himself». Tais informações são retomadas rapidamente em Rouse; Rouse, 1978, p. 351, n. 53, e, então, em Hunt, 1998, p. 26; o nome de William de Malmesbury era já brevemente assinalado em AA.VV., 1867, p. 507-9. Recentemente, o manuscrito foi catalogado para as Invectivae por Novokhatko, 2002, p. 277, sem, porém, atribuir-lhe nenhum valor especial, tanto que, na sua edição sucessiva (Berlin-New York 2009), esse não é mais mencionado. 
e IV da obra ${ }^{71}$ e, assim, como veremos em breve, o $L u c$. é efetivamente dividido em $\mathbf{m}$. Refiro o passo que nos interessa ${ }^{72}$, com mais precisão do que Reid e Pease:

Hic lib' p(ri)m' achademicorum in anglia non ivenitur. Sed nec secundus in quo catulus pro achademicis disputans introducitur sicut ex multis que in hiis libris duobus proxime scriptis animadverti potest. Terci' | vero et quartus lib' achademicorum hii duo sunt qui p(ro)prie lucullus appellantur . quia ịuniogr ${ }^{73}$ in uno introducitur lucullus contra achademicos disputans, in alt(er)o tullius ei pro achademicis respondet.

Independentemente, entre as duas guerras, Cant2 começou também a interessar aos estudiosos de William de Malmesbury e a ser examinado no seu conjunto do ponto de vista paleográfico: ponto de partida é a monografia de James, 1931, p. 21, mas dados seguros sobre o lugar de composição e sobre a comissão (William Gray, bispo de Ely 1454-78) chegaram apenas vinte anos depois, graças a R.A.B. Mynors:

MS. Dd. 13. 2 in the University Library is a big and rather handsome folio, containing the philosophical works of Cicero and some of his speeches, to which M. R. James has already drawn attention as descended in part ${ }^{74}$ from a Cicero-manuscript put together by our great twelfth-century historian William of Malmesbury. It is in a good Dutch or German hand [...]; the nature of its contents leaves little doubt that it was written in the Rhineland; and at the end is Per manus theoderici nycolai Werken de Abbenbroeck explicit anno Domini MCCCC44 alias 1444. An erased inscription on the flyleaf tells us that the book was given to Balliol College, Oxford, by William Gray bishop of Ely (1454-78), and this fits in very well, for we know that Gray, a man of noble family who was a great collector of books, had matriculated at the University of Cologne in December 1442, and this Cicero might well have been written in Cologne and to his order. And if we turn to the large section of Gray's library

${ }^{71}$ Se William tivesse podido ler também as cartas a Ático, teria descoberto a existência das duas versões do tratado; na ausência de tais informações, sua reconstrução é mais que plausível: «William reached this conclusion by analysing Div II 1,1, without the assistance of the letters Ad Atticum, and thus pre-empted the observation of Petrarch, made two centuries later after a period of considerable confusion about the identity of the Academicus Primus, as manifested by the manuscript tradition» (Hunt, 1998, p. 26).

${ }^{72}$ Citado amiúde sem especificar a sua exata localização em Cant2, que é $111 \mathrm{v}$ col. II 112r col. I, cf. supra n. 70 e Hunt, 1998, p. 26, n. 30. É de se notar que o mesmo conceito já havia sido expresso, em uma forma mais reduzida e com palavras diversas, já no início do Luc., em uma longa nota na margem interna da coluna I de 93r; todavia, incipit e explicit do Luc. referem as indicações liber primus e secundus, não tertius e quartus, cf. infra n. 80.

${ }^{73}$ Devo a Michael Reeve a exata leitura autóptica desta palavra eliminada, que é entendida como primeira tentativa de leitura, logo corrigida por in uno que segue. Em Bert, fólio 197r, lê-se minio no lugar de quia ... uno; a única outra diferença é a omissão de ei após tullius.

${ }^{74}$ A respeito deste in part voltaremos infra n. 88. 
still preserved at Balliol College, we find other work from the same hand ${ }^{75}$.

Há alguns anos, a rica monografia de R.M. Thomson reconstruiu finalmente a justa profundidade, psicológica bem como histórica, da atividade cultural de William de Malmesbury, atentando à sua constante e sistemática atividade de comentador dos clássicos ${ }^{76}$, que vemos refletir-se em Cant2 nas margens, no início e no fim do $L u c^{77}$. O seu conhecimento sobre Cícero é testemunhado não só pelos códices a ele atribuíveis, mas também pela presença de citações ciceronianas nas suas obras históricas: além dos diálogos e dos discursos presentes em Cant2, William aparenta ter conhecido alguns dos tratados retóricos e, talvez, o De legibus ${ }^{78}$.

No que diz respeito a essa coleção de informações, $\mathbf{B e r t}^{79}$ parece ter sido

${ }^{75}$ Mynors, 1950, p. 98, retomado por Reeve; Rouse, 1983, p. 81.

${ }^{76}$ A partir de «the short, bio-bibliographical preface giving information about the author and the historical context of each work. [...] Sometimes, too, William provided tables of contents» (Thomson, 2003, p. 36).

${ }_{77}^{77}$ Mas o Luc. não é o único tratado de Cant2 ao qual William reserva notas de comentário: os passos mais significativos são referidos em Thomson, 2003, p. 51-3. Quanto aos marginalia, esses frequentemente referem, de maneira abreviada, notícias presentes nas mais desenvolvidas introduções de William (cf. supra n. 72); outras vezes, no entanto, faz-me notar Michael Reeve per litteras, há referências a personagens ativos na segunda metade do século XII, como Ricardo de San Vítor († 1173, f. 313v, em relação às Tusculanae), Averróes († 1198), a Regra de São Francisco e outros mais, que deixam aberta a hipótese de que a atividade de glosa sobre o antígrafo de Cant2 foi continuada ainda algum tempo após a morte de William (cf. também James, 1931, p. 23-5, que provavelmente exagera ao falar de citações de autores «as late as the fourteenth century»).

${ }^{78}$ Assim Thomson, 2003, p. 55, com referência a Gesta regum Anglorum 374, 1; o mesmo assinala-me per litteras também a descoberta feita por Michael Winterbottom do partitivo operis ac muneris, hapax ciceroniano de leg. II, 6, que volta em um contexto sintático quase idêntico no Liber de Miraculis S. Mariae, 24, 4. Embora Schmidt, 1974, no seu atentíssimo exame do Fortleben medieval desse tratado, não nomeie jamais William de Malmesbury, manuscritos do De legibus de antígrafo francês, escritos na Inglaterra e descendentes de $\mathbf{V}$, estavam presentes na ilha e justamente no século XII, segundo o próprio Schmidt (cf. infra n. 92).

${ }^{79}$ Cartáceo ( 295 x $215 \mathrm{~mm}$ ), de 295 fólios, Bert é posterior a Cant2 ao menos un decênio: além da genérica fórmula "XV sec." que se encontra nos catálogos, devo a R. Cordonnier um exame das filigranas, que permitiu identificar uma «Lettre $P$ gothique simple, à long jambage bifurqué, surmontée d'un fleuron à quatre feuilles», correspondente aos nn B Briquet 8591 (Colmar 1452) e 8606 (Troyes 1470). Escrito por uma única mão em uma gótica cursiva de traço espesso e plena de abreviaturas (definida «absolutely typical Low Countries of the period» por Rodney Thomson, per litteras), Bert é de leitura difícil, em uma única coluna, com espelho de escrita muito amplo e margens sem notas, sem elementos de valor, afora as iniciais de capítulo acrescentadas em vermelho (com letrina) e as maíusculas retocadas e reavivadas, sempre coloridas. Contém Tusculanae (precedidas pela mesma citação do comentário de Gerolamo à carta paulina Ad Galatas, que se encontra em Cant2, antes de Tusc., cf. Thomson, 2003, p. 53), De natura deorum, De divinatione, De fato, Luc. (171v-196v), precedido pelos mesmos excerpta do De civitate Dei de Santo Agostinho (171r-171v) e seguido pelo mesmo comentário em primeira pessoa de William (196v-197v, cf. supra n. 72), Timaeus, Philippicae e, enfim, o Asclepius do pseudo-Apuleio (com o título Hermis Trismegisti Helera ad Asclepium allocuta, seu Asclepias de natura Deorum). Da história de Bert conhece-se somente a proveniência da abadia de SaintBertin, próxima a Saint-Omer (Pas-de-Calais), testemunhada pela indicação "616” no canto 
até agora esquecido, tanto pelos filólogos atentos ao Corpus Leidense quanto pelos medievalistas e pelos paleógrafos, não tendo sido objeto de nenhum estudo específico: se um mérito e uma função estas páginas têm, penso que poderiam ser os de sinalizar à comunidade científica e aos especialistas de William de Malmesbury em primeiro lugar a existência de um códice gêmeo do conhecido Cant2, à espera, como se dizia, de uma investigação adequada.

Além das coincidências textuais reunidas supra $n^{\circ} 8$, Bert e Cant 2 compartilham de um fator de mise en page absolutamente único: o texto do Luc., de fato, já constituído em dois livros como consequência da interpretação dos Academici libri, elaborada por William e supracitada, é ulteriormente subdividido em capítulos numerados (com algarismos quase sempre arábicos) de modo progressivo, mesmo que nem sempre idêntico nos dois códices. Um tal traço de modernidade e de independência, que não se limita ao Luc., mas se estende às outras obras filosóficas, não tem, até onde sei, paralelos na história manuscrita de Cícero, até antes das primeiras edições impressas ${ }^{80}$.

superior esquerdo do fólio 1r. Extremamente útil nesse sentido seria examinar as obras de Bert estranhas ao Corpus Leidense e, em particular, as Philippicae, cujo texto em Cant 2 foi já há um tempo identificado como paralelo ao de Bruxelas, Bibliothèque Royale, 14492, datado do fim do século XIV e início do XV (cf. Reeve; Rouse, 1983, p. 77). Esse manuscrito (indicado por $\pi$ no aparato OCT de A.C. Clark e em Reeve; Rouse, 1983; $P$, por sua vez, naquele de Cambridge de D.H. Berry para o Pro Sulla) é, a despeito disso, importante também para outros discursos ciceronianos (cf. Reeve; Rouse, 1983, p. 59; 81; Reeve, 1997, p. 334-5).

${ }^{80}$ William decide colocar a subdivisão entre o dois livros do Luc., no fim do capítulo 63 (Lucull' liber 2' incipit Bert Marcus. Tullius . Cicero. / Lucullus . liber primus explicit . I Incipit secundus Cant2), diversamente de manuscritos como Bon e Yal, que colocam a passagem no fim do $§ 62$, falando, porém, de livro III e IV (cf. supra n. 72). Em Bert, a numeração concerne a todos os tratados filosóficos presentes (cf. n. prec.), não às Philippicae nem ao texto pseudoapuleiano final. Apresento em seguida a subdivisão dos capítulos do Luc., seguindo Cant2 para a grafia (os capítulos sublinhados coincidem com o incipit dos $§ \S$ nas edições modernas): Cant 2 possui 1. talvez no início do $L u c$., mas a parte correspondente foi subtraída (f. 93, cf. supra n. 68); 2 § 4 sed quae; 3 § 5 ac vereor; 4 § 7 restat unum; 5 § quibus de rebus; 6 \$ 10 tum

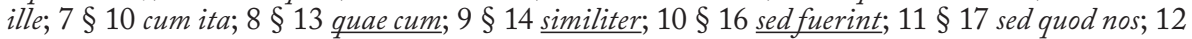
§ 18 Philo autem; 13 § 19 ordiamur; 14 § 22 quod si essent; 15 § 23 maxime vero; 16 § 24 atque etiam; 17 § 26 tamen ne; 18 § 27 ipsa autem; 19 § 28 ex hoc; 20 § 29 sed de inconstantia; 21 § 31

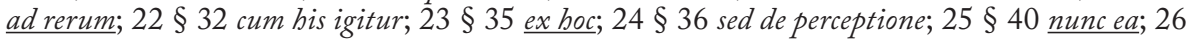
$\S 41$ quae autem; 27 § 43 hanc ego; 28 § 44 ergo si rebus; 29 § 45 sed; 30 § 47 primum conantur;

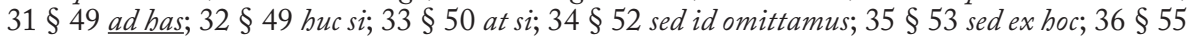

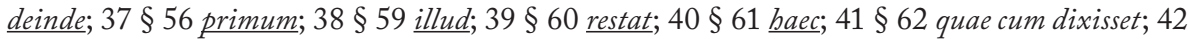
$\S 63$ tum mibi. Bert não possui nenhum sinal no início do tratado e põe o capítulo 1 no $§ 4$ (sed quae), com a consequência de que os capítulos sucessivos correspondem exatamente àqueles de Cant2, mas com um número a menos, até $41 \S 63$ tum mibi (voltarei a esta particularidade crucial infra n. 98). Para o livro II, Bert e Cant 2 possuem 1 § 64 me Catule (deixando poucas linhas iniciais, haec cum ... exorsus, sem indicação de capítulo); 2 \$66 sed non de me; 3 § 67 hanc conclusionem; 4 § 69 sed; 5 § 71 sed ex hoc cum eo; 6 § 74 furere; 7 § 76 quid; 8 § 76 satis multa; 9

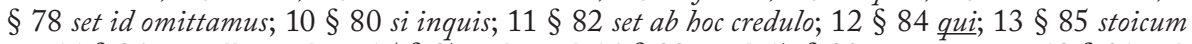

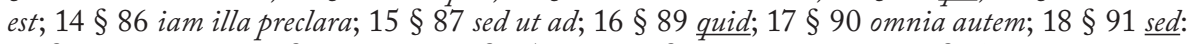

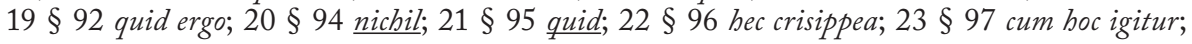


A partir de todos esses dados, podemos chegar à conclusão de que o $L u c$. de m, do qual Bert e Cant2 são cópias independentes (cf. supra n ${ }^{\circ}$ 9), era propriamente uma verdadeira "edição crítica com comentário", elaborada no século XII por William de Malmesbury a partir de $\mathbf{V}$ ou de uma cópia dele ( ${ }^{\circ} 1$ ), que chamaremos $\mathbf{w}$, de qualquer modo diversa de $\mathbf{v}\left(\mathrm{n}^{\circ} 2\right)$. Essa era caracterizada por intervenções textuais invasivas $\left(\mathrm{n}^{\circ}\right.$ 8), por uma subdivisão explícita em capitula, por introdução e posfácio com referência a outros textos, ciceronianos e não ciceronianos, enfim, por notas marginais de comentário, talvez continuados por sua escola. Tal quadro, seguramente excepcional para o século XII, parece, no entanto, encontrar apoio na reconstrução que R.M. Thomson oferece da atividade de William, sempre muito atento ao estilo ${ }^{81}$, cercado por uma équipe de escribas especialistas, que respondiam às suas ordens, e pronto para a intervenção edótica e filológica ${ }^{82}$; sobretudo, «William was concerned to provide good texts. A detailed study of this endeavour would prove rewarding. [...] it has been frequently noted that William was wont to correct his exemplar, usually unauthoritatively but always intelligently» ${ }^{83}$.

Um passo à frente fundamental foi dado recentemente por Robert Kaster, que identificou provas de leitura seguras por parte de William também das Vidas suetonianas $^{84}$. Nessa tradição, o estudioso identificou dois manuscritos gêmeos ${ }^{85}$ (como Bert e Cant2), com sinais evidentes de uma invasiva atividade conjectural. Essa foi examinada pelo estudioso segundo duas principais modalidades de intervenção, a saber, a modificação do ordo verborum em obediência a rígidos paradigmas de sucessão gramatical ${ }^{86}$ ou «changes that can only strike the modern

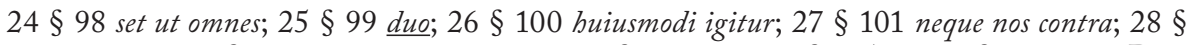

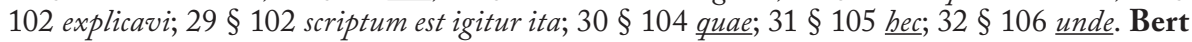
omite esse capítulo e continua do sucessivo com um número a menos, de 32 § 106 a $63 \S 148$, sempre, contudo, respeitando a localização de Cant2. Seguindo esse último, temos $33 \S 106$ et iam si comprehensio; 34 § 108 alterum; 35 § 109 et tamen illud; 36 § 111 ne illa; 37 § 112 nunc quid facere; 38 § 114 que tandem; 39 § 115 non me quidem; 40 § 117 quod; 41 § 118 princeps; 42

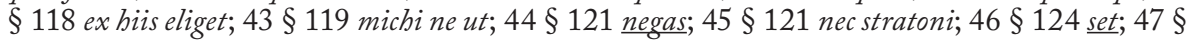

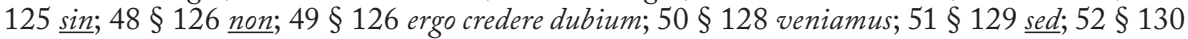

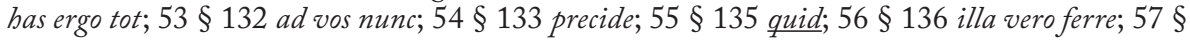
137 hec; 58 § 138 testatur; 59 § 139 laboro ut; 60 § 141 nibil; 61 § 142 venio; 62 § 144 deinde ad illam; $63 \S 147$ verum; $64 \S 148$ tum. Registro, enfim, ainda o fato que o início retardado da numeração, se para o Luc. marca uma distinção entre os dois códices, torna-se um fator partilhado nos outros tratados: as Tusculanae trazem, de fato, seja em Bert seja em Cant2, o capitulum primum no 9 (malum mibi videtur), o De fato no 33 (Quibus acceptis Quid ergo).

${ }^{81}$ Thomson, 2003, p. 21.

${ }^{82}$ Thomson, 2003, p. 24 recorda «his ability to deploy his wonderful knowledge of his texts to critical advantage».

${ }^{83}$ Thomson, 2003, p. 35, em referência a Iordanes, aos Sermões de Leão Magno e a Tertuliano.

${ }^{84}$ Kaster, 2016.

${ }^{85}$ London, British Library, Royal 15 C.iv, do século XIII, e Oxford, Bodleian Library, Lat.class. d.39 do terceiro quarto do século XII.

${ }^{86}$ Kaster identifica três deles em particular, que encontram alguma confirmação em alguns dos casos de Bert e Cant2 assinalados supra, no n 8, o que demonstra quanto é necessário um exame 
eye as willful tampering». Sobretudo essas últimas justificam a conclusão segundo a qual «the most prodigiously fertile corrector that the text of Suetonius has known was also its most willful and aggressive reader ${ }^{87}$.

Restam ainda a serem discutidos dois problemas estreitamente conexos, a respeito dos quais, todavia, no estado atual das pesquisas, só posso apresentar respostas provisórias: as características de $\mathbf{w}$ e a origem de Bert e Cant2. Dado por certo o caráter unitário de Cant2 ${ }^{88}$, concentremo-nos no Corpus Leidense. Embora a atividade de William fosse desenvolvida quase que integralmente na Grã-Bretanha, menções de suas viagens à França tornaram-se conhecidas recentemente, mas dois elementos tornam improváveis que, durante uma delas, ele tivesse tido contato diretamente con $\mathbf{V}^{89}$. O primeiro é o fato que o conteúdo de $\mathbf{m}$ é reduzido e ligeiramente variado se comparado ao de $\mathbf{V}$ :

\begin{tabular}{|c|c|c|c|c|}
\hline $\begin{array}{l}\text { V } \\
\text { Bert } \\
\text { Cant22 }\end{array}$ & $\begin{array}{l}\text { nat. } \\
\text { nat. } \\
\text { nat. }\end{array}$ & Tim. & $\begin{array}{l}\text { div. fat. par. } \\
\text { div. fat. } \\
\text { div. fat. }\end{array}$ & $\begin{array}{l}\text { Luc. } \\
\text { Luc. Tim. } \\
\text { Luc. Tim. }\end{array}$ \\
\hline
\end{tabular}

enquanto dificilmente um leitor voraz como William teria excluído da sua cópia um texto fascinante como o De legibus ${ }^{90}$. Em segundo lugar, foi o próprio William que escreveu, como recordar-se-á, hic liber primus Achademicorum in Anglia non invenitur, frase da qual creio ser legítimo deduzir que tudo o que William

sistemático também sob esse aspecto: «adjectival information with a merely attributive meaning is made to follow the noun it modifies» (como no $§ 4$ Graecis litteris $\omega \mathbf{v}$ litteris grecis $\mathbf{m}$ ); «adverbial information is made to precede the word or phrase it modifies»; «words that "go together" are made to stand together, and instances of hyperbaton are eliminated» (Kaster, 2016, p. 127).

${ }^{87}$ Kaster, 2016, p. 130 (cf. Malaspina, 2015, p. 35-6).

${ }^{88}$ É a tese mais recente (Thomson, 2003, p. 55, citado infra n. 96), segundo a qual tudo do manuscrito deriva da atividade de William, cujo peritexto exegético acompanha também os discursos presentes. Anteriormente, tanto James, 1931, quanto Mynors, 1950, ou Reeve; Rouse, 1983, p. 59, julgaram mais prudente considerar os discursos dependentes de uma tradição diversa: "A Cicero-corpus deriving from the English renaissance in the twelfth century and a group of his speeches which had been among the most distinguished discoveries of the Italian renaissance in the fourteenth» (Mynors, 1950, p. 98 e supra n. 75).

${ }^{89}$ Sobre a presença de William na França, cf. o comentário aos Gesta regum Anglorum (Thomson; Winterbottom, 1999), p. 170, 232, que me foi indicado por Michael Reeve; anteriormente, a vulgata opinio era que «William never travelled abroad» (Reeve; Rouse, 1983, p. 81). De $\mathbf{V}$ ignoramos a localização exata no período do século IX até o seu reaparecimento em Anvers, no século XV (cf. Rouse, 1983, p. 126, e supra n. 32).

${ }_{90}$ Recordo que o desprendimento do De legibus de V (cf. supra § 3.) foi causado pelo destaque dos últimos cadernos e provocou também a perda de $1 / 3$ do Luc., enquanto, em $\mathbf{m}$, não se nota nenhuma solução de continuidade no $§ 104$ do Luc. nem diferença alguma na parte hoje faltante em $\mathbf{V}$. Tal dado de fato torna igualmente improvável também a hipótese inversa, isto é, aquela de uma peregrinação temporária de $\mathbf{V}$ na Inglaterra. Como se disse (cf. supra n. 78), parece que William conhecia o texto do De legibus, mesmo se não possuímos manuscritos a ele referentes dentre aqueles em nosso domínio. 
havia lido invenitur in Anglia, ou seja, dito de outra maneira, que as suas fontes manuscritas - e, portanto, também $\mathbf{w}$ - eram exclusivamente inglesas. Portanto, resta apenas imaginar que, sobre $\mathbf{V} / \mathbf{V}^{2}$, tivesse sido copiada ${ }^{91}$ uma segunda cópia $\mathbf{w}$, distinta de $\mathbf{v}$, sem o De legibus, e que essa tivesse chegado à Inglaterra antes do século XII, permitindo, assim, que William a partir dela produzisse $\mathbf{m}$. A ausência do De legibus em w não constitui um problema: comparados ao grande formato do Corpus Leidense, de fato, os códices dos séculos X-XII, conservados ou reconstruíveis, mostram uma tendência a constituírem-se em grupos mais simples. Dos oito tratados iniciais do Corpus, passa-se, de fato, aos cinco ou seis de $\mathbf{m}$ e aos três de $\mathbf{N}$, mesmo que seja irrealista tentar compreender as razões que levaram, a cada vez, às inclusões e às exclusões ${ }^{92}$. Somente a partir do século XIII e em plena idade humanística o desejo de encerrar os opera omnia ciceronianos em um só volume levou a mudar a tendência e a reunir manuscritos-monstrum com dezenas e dezenas de item, de que Cant2 é um exemplo não desprezável.

Chegamos, assim, ao segundo problema, que é um corolário do primeiro: a única crítica que também R.M. Thomson faz à atividade de William é a de não ter sabido dar-lhe continuidade após a sua morte, costituindo uma escola de modo a sobreviver também ao desaparecimento de sua liderança carismática. Neste sentido, não há traços de uma continuação de sua atividade edótica e exegética ${ }^{93}$, como confirma, em relação ao $L u c$., a descendência muito reduzida de $\mathbf{m}$, se comparada a v. Neste quadro, como é possível que $\mathbf{m}$ se encontrasse no século XV não só em Saint-Bertin ${ }^{94}$, mas logo em Colônia, onde foi copiado Cant2 ${ }^{95}$ ? A resposta mais econômica para este último manuscrito foi dada por R.H. Rouse e M.D. Reeve, seguidos por R.M. Thomson: o bispo Gray teria partido da Inglaterra levando consigo - por algum motivo desconhecido - $\mathbf{m}$ (que imaginamos ter sido descoberto

${ }^{91}$ Também essa já no século IX? Cf. supra $\$ 4.1$.

${ }^{2}$ Cf. supra n. 30, e Schmidt, 1974, p. 162 («eine plausible Erklärung scheint schwer zu finden zu sein»). Schmidt, 1974, p. 169, identifica, sempre no século XII, um ulterior descendente de V (que chama v', p. 173), reduzido a quatro item porque contém o De legibus, mas não Timaeus, Paradoxa e Luc.: «Wir hatten oben die Handschrift $P$ in der Bretagne zu lokalisieren versucht, einem Gebiet, das im 12. Jh. mit den westlichen und nordwestlichen Teilen Frankreichs zusammen mit England derselben Dynastie unterstand. Bei der entsprechend engen Verflechtung französischer und englischer Kultur darf mit großer Wahrscheinlichkeit vermutet werden, daß die De-legibus-Exemplare, die in einigen wichtigeren Bibliotheken des mittelalterlichen England anzutreffen sind, aus Frankreich importiert oder von französischen Vorlagen kopiert worden sind» (Schmidt, 1974, p. 224, itálico meu). Ora, Schmidt fazia tal afirmação a propósito do antígrafo do Fabricianus, isto é, p, que já conhecemos (cf. supra nn. 18 e 55 ) e que descende de $\mathbf{V}$ por meio do citado v', mas essa afirmação poderia ser repetida também para William de Malmesbury e o códice $\mathbf{m}$ do Luc. De resto, no Regius, proveniente pelo De legibus sempre por $p-v^{\prime}$ (cf. ainda n. 55), Luc., Timaeus e Paradoxa foram reintegrados (Schmidt, 1974, p. 225), evidentemente trazendo o texto de uma tradição diversa. Videant doctiores.

${ }_{93}$ Além do enriquecimento das notas marginais em Cant2 (cf. supra n. 77).

${ }^{94}$ Pas-de-Calais permaneceu território inglês até o ano 1559 (cf. n. 92).

${ }^{95}$ Cf. supra n. 75. 
dentre os legados de William de Malmesbury em alguma abadia insular) junto com outros códices, e teria usufruído do conhecimento do copista Werken, que conhecera em Colônia, para confiar-lhe a cópia de Cant 2 a partir de $\mathbf{m}^{96}$.

Com a descoberta de Bert, essa hipótese demonstra-se, no entanto, inadequada, pois ainda não explica como $\mathbf{m}$ teria encontrado seu caminho de Colônia para Pas-de-Calais entre os anos 1444 e 1470 ${ }^{97}$ : tal incerteza exorta à prudência e torna ainda mais necessário um exame sistemático dos dois manuscritos, como já se disse. Gostaria, contudo, de propor uma interpretação que peço seja considerada como meramente hipotética no estado atual: todos os problemas de sobreposição geográfica seriam resolvidos se postulássemos que Bert e Cant2 derivam de dois antígrafos diversos, duas cópias distintas do trabalho de William (que podemos chamar $\mathbf{m}$ e $\mathbf{m}$ '), uma sepultada em Saint-Bertin, a outra exumada por Gray na Inglaterra, testemunhos de duas fases diversas do trabalho exegético. Pequenos elementos codicológicos permitem-me considerar a hipótese não completamente infundada, ficando seguro de que ela poderá ser confirmada ou desmentida apenas com um estudo não restrito ao Luc.: em primeiro lugar, a correção similiter do $§ 14$, exclusiva de Cant2, parece pressupor um antígrafo em que a atividade conjectural de William tivesse dado algum passo à frente, se comparado ao estágio representado por Bert; e que esse códice se refira a uma fase menos avançada dos trabalhos parece-me subentendido, sobretudo, pelas estranhas omissões de Bert ao referir os números de capítulo de William para o $L u c$. e por outras diferenças de mise en page entre os dois códices ${ }^{98}$.

\section{STEMMA CODICUM}

96 «If the annotation was done in England, as seems most likely, then it means that Gray brought all the exemplars [compreendidos os antígrafos de Oxford, Balliol College, 79 e 125] with him to Cologne. On this basis I am inclined, though tentatively, to accept the whole of the Cicero-collection in CUL Dd. 13. 2. as William's» (Thomson, 2003, p. 55; cf. também Reeve; Rouse, 1983, p. 81). Gray estava em viagem pela Itália e, segundo uma convincente proposta de R.A.B. Mynors, teria deixado Colônia levando consigo não só Cant2, mas também Werken, que, aproximadamente no ano 1450, se separou dele para voltar à Inglaterra a serviço de um amigo de Gray, Richard Bole (Mynors, 1950, p. 99-101).

${ }^{97} \mathrm{Se} \mathbf{m}$ permaneceu em posse de Gray, por que ele solicitou uma segunda cópia desse (reduzida e menos elegante que a primeira) para, depois, deixá-la em Saint-Bertin? (Gray voltou de Roma à Inglaterra quando foi nomeado bispo de Ely no ano 1454). E como pensar que Gray se pudesse separar de um cimélio de William de Malmesbury como $\mathbf{m}$, que levara consigo em viagem da Inglaterra? E mesmo se tivesse sido assim, como explicar a chegada de $\mathbf{m}$ à região de Pas-de-Calais?

${ }_{98}$ É como se, em outras palavras, Cant 2 refletisse a versão definitiva e oficial do trabalho de William, que compreende os Paradoxa, ausentes em Bert, das conjecturas mais atualizadas e de uma numeração de capítulo regularizada e generalizada. Já dissemos, de fato, que a numeração do Luc. não parte, em Bert, do início, como em Cant2, mas exclui sem um claro motivo o equivalente a algum $\S$ moderno (cf. supra n. 80, também para o início retardado da numeração no "segundo" livro do Luc.). Outra peculiaridade é que as Philippicae de Bert não possuem numeração, diferentemente de todos os discursos de Cant2 (agradeço a Michael Reeve o exame autóptico). Também a ausência de marginalia em Bert poderia referir uma diferença de antígrafo, se não se tratou de uma escolha redacional consciente do copista. 
Tudo isso leva-nos ao seguinte esboço de estema para a família de $\mathbf{V}$ :

séc. IX

séc. IX?

séc. XII

séc. XII-XIII

séc. XIII

séc XIII-XV

séc. XIV

séc XIV-XV

$\sec \mathrm{XV}$

Par
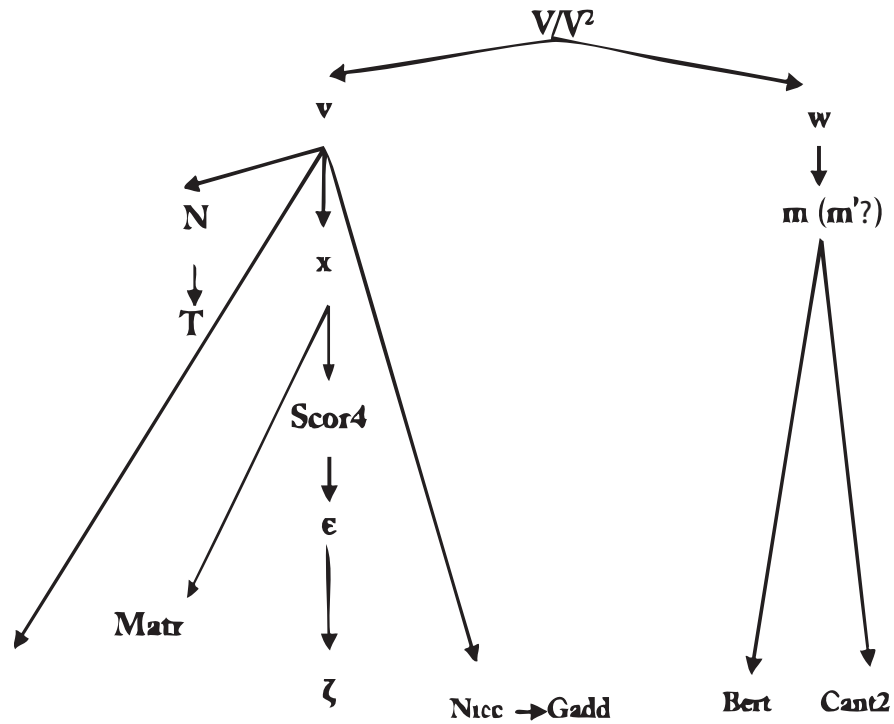

\section{Conclusões}

Enquanto a reconstrução estemática da família de $\mathbf{F}$ não tem nenhuma incidência sobre a constituição do texto de $L u c$., limitando-se a ser uma necessária contribuição para a história da tradição e uma ocasião para especificar melhor a atribuição de variantes e conjecturas, seria justo dizer o mesmo para a descendência de $\mathbf{V}$ se um terço do tratado desse manuscrito não tivesse sido perdido. Construir o estema dos descendentes de $\mathbf{V} / \mathbf{V}^{299}$ importa para a edição crítica do Luc. porque permite aos $\S \S 104-48$ substituir a referência imprecisa apenas em $\mathbf{N}^{100}$, amparando-se nas lições de duas classes distintas: uma, $\mathbf{m}$, representada por Bert e Cant2, sistematicamente interpolada por William de Malmesbury e, portanto, tendencialmente menos fidedigna; outra, v, constituída por 33 testemunhos e, ao menos na origem, menos contaminada e corrompida. Pelo princípio da eliminatio codicum descriptorum, podemos reconstruir $\mathbf{v}$ com base apenas nas lições de N Scor4 Matr Nicc Par9 ${ }^{101}$.

Quanto à história da tradição, a pesquisa aqui desenvolvida permitiu, de

${ }^{99}$ Sobre $\mathbf{V}^{1}$, cf. supra n. 9.

${ }^{100}$ Cf. supra nn. 31 e 33.

${ }^{101}$ Para dar um único exemplo, § 109 in navigando BAS et in navigando vm permite-nos demonstrar que o acréscimo de et se encontrava, sim, em $\mathbf{V}$, mas somente como interpolação de $\mathbf{V}^{2}$. 
um lado, "descobrir" Bert, cuja natureza de gêmeo do mais conhecido Cant2 se ignorava, e colocar, portanto, um pouco de luz sobre as especificidades de m, que requereriam, de qualquer modo, um suplemento de pesquisa; de outro, precisar a gênese do Luc. em muitos manuscritos, colocando em evidência as claras diferenças em relação à reconstrução feita por P.L. Schmidt para o De legibus, cujo ramo $p$ corre paralelo, em sentido cronológico e geográfico, a m e, sobretudo, a $\mathbf{v}$, amiúde entrecortando-se e muito raramente sobrepondo-se perfeitamente, como ocorre no caso da descendência de Gadd. 


\section{REFERÊNCIAS BIBLIOGRÁFICAS}

\section{Sigla codicum ${ }^{102}$}

$\begin{array}{ll}\text { A } & \text { Leiden, Bibliotheek der Rijksuniversiteit, Voss. lat. F } 84 \\ \text { B } & \text { Leiden, Bibliotheek der Rijksuniversiteit, Voss. lat. F } 86 \\ \text { F } & \text { Firenze, Biblioteca Medicea Laurenziana, S. Marco } 257 \\ \text { H } & \text { Leiden, Bibliotheek der Rijksuniversiteit, B.P.L. } 118 \\ \text { N } & \text { Paris, Bibliothèque Nationale, lat. 17812 } \\ \text { S } & \text { El Escorial, Real Biblioteca de San Lorenzo, R.I.2 } \\ \text { T } & \text { Tours, Bibliothèque municipale, 688 } \\ \text { V } & \text { Wien, Österreichische Nationalbibliothek, 189 }\end{array}$

$\begin{array}{ll}\text { Ball } & \text { Oxford, Balliol College, 248 D } \\ \text { Bert } & \text { Saint-Omer, Bibliothèque Municipale, 652 } \\ \text { Bon } & \text { Bologna, Biblioteca universitaria, 2228 (lat. 1096) } \\ \text { Cant2 } & \text { Cambridge, University Library, Dd.XIII.2 } \\ \text { Cas } & \text { Roma, Biblioteca Casanatense, 868 } \\ \text { Chis } & \text { Città del Vaticano, B.A.V., Chigi H. V. 147 } \\ \text { Chris } & \text { London, Christie's 25.6.1986, lot 212 } \\ \text { Corv } & \text { New York, Pierpont Morgan Library, M 497 } \\ \text { Dresd1 } & \text { Dresden, Sächsische Landesbibliothek, Dc 106 } \\ \text { Fes } & \text { Firenze, Biblioteca Medicea Laurenziana, Fiesole 188 } \\ \text { Gadd } & \text { Firenze, Biblioteca Medicea Laurenziana, ex Gaddi, Plut. 90 sup. 78 } \\ \text { Glas } & \text { Glasgow, University Library, Hunterian Museum T.2.14 (56) } \\ \text { Gud } & \text { Wolfenbüttel, Herzog-August-Bibliothek, Gud. lat. 2 (4306) } \\ \text { Har1 } & \text { London, British Library, Harley 6327 } \\ \text { Laur3 } & \text { Firenze, Biblioteca Medicea Laurenziana, Plut. 83, 7 } \\ \text { Linc } & \text { Oxford, Lincoln College, 38 } \\ \text { Lond } & \text { London, private collection of Nicholas Barker } \\ \text { Mag1 } & \text { Firenze, Biblioteca Nazionale, Magl. XXIX, 199 } \\ \text { Matr } & \text { Madrid, Biblioteca Nacional, 7813 (V 227) } \\ \text { Mon2 } & \text { München, Bayerische Staatsbibliothek, clm 15958 } \\ \text { Mon3 } & \text { München, Bayerische Staatsbibliothek, clm 30019 } \\ \text { Neap } & \text { Napoli, Biblioteca Nazionale, ex Vienna lat. 57 } \\ \text { Neap2 } & \text { Napoli, Biblioteca Nazionale, ex Vienna lat. 43 } \\ \text { Nicc } & \text { Firenze, Biblioteca Medicea Laurenziana, S. Marco 272 } \\ \text { Ott } & \text { Città del Vaticano, B.A.V., Ottobon. lat. 1478 } \\ & \end{array}$

102 São referidas apenas os sigla dos códices citados no presente artigo. Para o elenco completo, cf. supra n. 18. 


\begin{tabular}{|c|c|}
\hline Par & Paris, Bibliothèque Nationale, lat. 6283 \\
\hline Par3 & Paris, Bibliothèque Nationale, lat. 6597 \\
\hline Par4 & Paris, Bibliothèque Nationale, lat. 17154 \\
\hline Par5 & Paris, Bibliothèque Nationale, lat. 7784 \\
\hline Par6 & Paris, Bibliothèque Nationale, lat. 9320 \\
\hline Par7 & Paris, Bibliothèque Nationale, lat. 6374 \\
\hline Par8 & Paris, Bibliothèque Nationale, lat. 6375 \\
\hline Par9 & Paris, Bibliothèque Nationale, lat. 14752 \\
\hline Parm & Parma, Biblioteca Palatina, Parmense 1987 \\
\hline Pat & Padova, Biblioteca del Seminario Vescovile, ms. XXIV \\
\hline Reg & Città del Vaticano, B.A.V., Reg. lat. 1481 \\
\hline Schl & Schlägl, Prämonstratense Stiftsbibliothek, Cpl. 106. [454.b].58 \\
\hline Scor4 & E1 Escorial, Real Biblioteca de San Lorenzo, V.III.6 \\
\hline Trec & Troyes, Bibliothèque Municipale, 552 \\
\hline Vat4 & Città del Vaticano, B.A.V., Vat. lat. 3245 \\
\hline Yal & $\begin{array}{l}\text { New Haven, Yale University, Beinecke Rare Book and } \\
\text { Manuscript Library, } 284\end{array}$ \\
\hline$\varepsilon$ & $\begin{array}{r}\text { consensus codicum (Scor4) Gud Mag1 Par Par4 Par5 Par6 } \\
\text { Par7 Sch1 Trec }\end{array}$ \\
\hline$\zeta$ & $\begin{array}{r}\text { consensus codicum Glas Harl Mon2 Neap Neap2 Ott Par8 } \\
\text { Parm Pat }\end{array}$ \\
\hline m & fons communis codicum Bert Cant 2 \\
\hline m’ & alter fons (?) codicum Bert Cant2 \\
\hline $\mathbf{v}$ & fons communis codicum NT Nicc Par9 $\times \varepsilon \zeta$ \\
\hline $\mathbf{w}$ & fons sive antigraphon codicis $\mathbf{m}$ \\
\hline $\mathbf{x}$ & fons communis codicum Matr et Scor 4 \\
\hline$\omega$ & consensus codicum $\mathbf{B A V}(\mathbf{S})$ sive archetypi lectio \\
\hline
\end{tabular}

\section{Fontes}

\section{II.1. EdiçõEs dos ACADEMICI/LuCULLUS}

M. TUlLIUS CICERO. Scripta philosophica. Conradus Sweynheym Arnoldus Pannartzque. Romae 1471 [editio princeps].

M. TULLII CICERONIS Opera Omnia Quae Exstant. A Dionysio Lambino Monstroliensi emendata. Parisiis 1566. Tomus quartus Lutetiae 1565, p. 10-39; 485-6.

M. TULLII CICERONIS Academica. Recensuit, variorum notis suas immiscuit, et Hadr. Turnebi Petrique Fabri Commentarios adjunxit J. Davisius. Cantabrigiae 1725. 
M. TULLI CICERONIS Academica. The text revised and explained by J. S. Reid. London $1874^{1} 1885^{2}$.

M. TULLI CICERONIS Paradoxa Stoicorum, Academicorum reliquiae cum Lucullo, Timaeus, De natura deorum, De divinatione, De fato. Fasc. I (par. Ac. Luc. Tim.) edidit O. Plasberg. Lipsiae 1908.

M. TULLI CICERONIS Academicorum reliquiae cum Lucullo. Rec. O. Plasberg. Lipsiae 1922 [= Stutgardiae 1980. 1996].

CICERO. De natura deorum, Academica. With an English translation by $\mathrm{H}$. S. Rackham. Cambridge-London 1967.

CICERO. Hortensius, Lucullus, Academici libri. Lat.-dt., hrsg., übers. und komm. von L. Straume-Zimmermann, F. Broemser und O. Gigon. München 1990.

CICERONE. Libri academici. Scelta di passi con traduzione italiana a cura di E. Riganti. Bologna 1994.

HALTENHOFF, A. Kritik der akademischen Skepsis: ein Kommentar zu Cicero, Lucullus 1-62. «Studien zur alten Philologie». Frankfurt a.M. 1998.

CICERO. Akademische Abhandlungen. Lucullus. Lateinisch-deutsch, Text und Übersetzung von C. Schäublin, mit einer Einleitung von A. Graeser und C. Schäublin und Anmerkungen von A. Bächli und A. Graeser. Hamburg 1998.

CICERO. On Academic Scepticism. Translated, with Introduction and Notes, by C. Brittain. Indianapolis Cambridge 2006.

CICÉRON. Les Académiques. Academica. Traduction, notes et bibliographie par J. Kany-Turpin. Introduction par P. Pellegrin. Paris 2010.

\section{II.2. OUTRAS EDIÇÕES SIGNIFICATIVAS}

M. TUlli CICERONIS De divinatione libri duo. Edited by A.S. Pease. Urbana 1920 [= Darmstadt 1963].

CICERONIS Paradoxa Stoicorum. Edidit R. Badalì. Centro di Studi Ciceroniani. Roma 1968.

M. TULLIUS CICERO. De natura deorum, livre I. Édition et traduction avec commentaire par M. van den Bruwaene. Collection Latomus. Bruxelles 1970.

M.T. CICERONIS De finibus bonorum et malorum libri quinque. Ed. L.D. Reynolds. Oxford 1998. 
CICERO's Topica. Edited with an Introduction, Translation, and Commentary by T. Reinhardt. Oxford 2003.

M. TULLIUS CICERO. De finibus bonorum et malorum. Ed. C. Moreschini. Bibliotheca Teubneriana. München Leipzig 2005.

M. TULLI CICERONIS De re publica, De legibus, Cato Maior de senectute, Laelius de amicitia. Recensuit brevique adnotatione critica instruxit J. G. F. Powell, Oxonii 2006.

WILLIAM OF MALMESBURY. Gesta regum Anglorum. The history of the English kings. V. II. General Introduction and Commentary by R.M. Thomson in collaboration with M. Winterbottom, Oxford 1999.

\section{Estudos}

AA.VV. A Catalogue of the Manuscripts preserved in the Library of the University of Cambridge. Cambridge 1856, v. I [on line em Archive.org].

ANTOLÍN, G. Catálogo de los códices latinos de la Real Biblioteca del Escorial, Madrid 1910-1916.

BADALİ, R. Sui codici dei Paradoxa di Cicerone. Rivista di Cultura Classica e Medioevale. Roma, v. 10, p. 27-58, 1968.

BANDINI, A.M. Catalogus codicum Latinorum Bibliothecae Mediceae Laurentianae, 4 voll., Florentiae 1774-1776.

VON BÜREN, V. Auxerre, lieu de production de manuscrits? In: SHIMAHARA, S. (ed.), Études d'exégèse carolingienne, autour d'Haymon d'Auxerre. Atelier de recherches, Centre d'Études médiévales d'Auxerre. 25-26 avril 2005. Turnhout 2007, p. 167-86.

DE ANDRÉS MARTÍNEZ, G. Inventario general de manuscritos de la Biblioteca Nacional. XII (7001 a 8499). Madrid 1988.

DE LA MARE, A.C. Vespasiano da Bisticci as Producer of classical Manuscripts in Fifteenth-Century Florence. In: CHAVANNES-MAZEL, C.A.; SMITH, M.M. (edd.). Medieval Manuscripts of the Latin Classics: production and use. Proceedings of the Seminar in the history of the book to 1500 (Leiden 1993). Los Altos-London 1996, p. 166-207.

DE ROBERTIS, T.; TANTURLI, G.; ZAMPONI, S. (edd.). Coluccio Salutati e l'invenzione dell'Umanesimo. Firenze, Biblioteca Medicea Laurenziana. 2 novembre 2008-30 gennaio 2009. Firenze 2008.

GASPARRI, F. Introduction à l'histoire de l'écriture. Turnhout 1994.

GENTILE, S. Traversari e Niccoli, Pico e Ficino: note in margine ad alcuni 
manoscritti dei Padri. In: CORTESI, M.; LEONARDI, C. (edd.). Tradizioni patristiche nell'Umanesimo. Atti del Convegno. Firenze, 6-8 febbraio 1997. Firenze 2000.

HALM, C. Zur Handschriftenkunde der Ciceronischen Schriften. Programm Maximilians-Gymnasiums. München 1850.

HUNT, T.J. A textual history of Cicero's “Academici libri”. «Mnemosyne Supplementum» 181. Leiden 1998.

JAMES, M.R. Two Ancient English Scholars, St. Aldhelm and William of Malmesbury. Glasgow 1931.

KASTER, R.A. Making Sense of Suetonius in the Twelfth Century. In: GRAFTON, A.; MOST, G. (edd.) Canonical Texts and Scholarly Practices. A Global Comparative Approach. Cambridge 2016, p. 90-109.

LÉVY, C. Cicero Academicus. Roma 1992.

MAGNALDI, G. Il De finibus bonorum et malorum di Cicerone: due edizioni a confronto. Bollettino di Studi latini. Napoli, v. 37, p. 623-38, 2007.

MALASPINA, E. Primae notulae ad Luculli Ciceroniani recentiores recensendos. In: BALBO, A.; BESSONE, F.; MALASPINA, E. (edd.). "Tanti affetti in tal momento". Studi in onore di G. Garbarino. Alessandria 2011, p. 547-54 [on line no site da SIAC em: http://www. tulliana.eu/documenti/Malaspina_78_Garbarino_2011.pdf].

MALASPINA, E. In Anglia invenitur: come Guglielmo di Malmesbury leggeva e soprattutto correggeva Cicerone nel XII secolo. In: P. DE PAOLIS (ed.). XXXIV Certamen Ciceronianum Arpinas, Dai papiri al XX secolo. L'eternità di Cicerone. Cassino 2015, p. 31-52.

MALASPINA, E. Recentior non deterior: Escorial R.I.2. e una nuova constitutio textus del Lucullus di Cicerone. Paideia. Cesena, v. 78, 2018.

MALASPINA, E.; BORGNA, A.; CASO, D.; LUCCIANO, M.; SENORE, C. I manoscritti del Lucullus di Cicerone in Vaticana: valore filologico e collocazione stemmatica. Miscellanea Bibliothecae Apostolicae Vaticanae, Città del Vaticano, v. 20, p. 589-620, 2014.

MYNORS, R.A.B. A Fifteenth-Century Scribe: T. Werken. Transactions of the Cambridge Bibliographical Society. Cambridge, v. 1, 2, p. 97-104, 1950.

NOVOKHATKO, A. Eine Liste der Handschriften der im Sallust und Cicerocorpus überlieferten Invektiven (Sallustii in Ciceronem et invicem Invectivae). Eikasmos. Bologna, v. 13, p. 273-86, 2002.

OAKLEY, S. The 'Puccini' Scribe and the Transmission of Latin Texts in 
Fifteenth-century Florence. In: BLACK, R.; KRAYE, J.; NUVOLONI, L. (edd.). Palaeography, Manuscript Illumination and Humanism in Renaissance Italy: Studies in Memory of A. C. de la Mare. London 2016, p. 345-64.

OUY, G. Les manuscrits de l'abbaye de Saint-Victor. Catalogue établi sur la base du répertoire de Claude de Grandrue (1514). Turnhout 1999.

PELLEGRIN, É. Les manuscrits de Loup de Ferrières. À propos du ms. Orléans 162 (139) corrigé de sa main. In: - . Bibliothèques retrouvées: manuscrits, bibliothèques et bibliophiles du Moyen Âge et de la Renaissance. Recueil d'études publiées de 1938 à 1985. Paris 1988, p. 131-57.

REEVE, M.D. Before and after Poggio. Some manuscripts of Cicero's speeches. Rivista di Filologia e di Istruzione Classica. Torino, v. 112, p. 266-84, 1984.

REEVE, M.D. The Circulation of Classical Works on Rhetoric from the 12th to the 14th Century. In: LEONARDI, C.; MENESTÒ, E. (edd.). Retorica e poetica tra i secoli XII e XIV. Atti in onore e memoria di E. Franceschini, Trento e Rovereto. 3-5 ottobre 1985. Firenze-Perugia 1988, p. 109-24.

REEVE, M.D. Review of MASLOWSKI, T. (ed.). M. Tullius Cicero. Orationes in P. Vatinium testem, Pro M. Caelio. Stutgardiae-Lipsiae 1995. Rivista di Filologia e di Istruzione Classica. Torino, v. 155, p. 3337, 1997.

REEVE, M.D.; ROUSE, R.H. Cicero. Speeches. In: REYNOLDS, L.D. (ed.). Texts and Transmission. A Survey of the Latin Classics. Oxford 1983, p. 54-98.

RICCIARDI, A. L'epistolario di Lupo di Ferrières. Intellettuali, relazioni culturali e politica nell'età di Carlo il Calvo, Spoleto 2005.

RONCONI, A. Il cursus medievale e il testo di Cicerone. Studi Italiani di Filologia Classica. Firenze, v. 11, p. 97-120, 1934.

ROUSE, R.H. De natura deorum, De divinatione, Timaeus, De fato, Topica, Paradoxa Stoicorum, Academica priora, De legibus. In: REYNOLDS, L.D. (ed.). Texts and Transmission. A Survey of the Latin Classics. Oxford 1983, p. 124-8.

ROUSE, R.H.; ROUSE, M. The "Florilegium Angelicum", its origin, content and influence. In: ALEXANDER, J.J.G.; GIBSON, M.T. (edd.). Medieval Learning and Literature. Essays R. W. Hunt. Oxford 1976, p. 66-114.

ROUSE, R.H.; ROUSE, M.A. The Medieval Circulation of Cicero's Posterior 
Academics and De Finibus Bonorum et Malorum. In: PARKES, M.B.; WATSON, A.G. (edd.). Medieval Scribes, Manuscripts, and Libraries: Essays presented to N.R. Kerr. London 1978, p. 333-67.

SCHMIDT, P.L. Die Überlieferung von Ciceros Schrift "de legibus" in Mittelalter und Renaissance. München 1974.

SENORE, C. Il ruolo di El Escorial, V.III.6 e dei suoi discendenti nella tradizione manoscritta del Lucullus. Ciceroniana on line. Torino-RomaParis, v. 1, 1, p. 157-91, 2017 [on line em http://www.ojs.unito.it/index. $\mathrm{php} / \mathrm{COL} /$ article/view/2194].

THOMSON, R.M. William of Malmesbury. Woodbridge $1987^{1} 2003^{2}$.

THOMSON, R. M.; DOLMANS, E.; WINKLER E. A. (edd.), Discovering William of Malmesbury. Woodbridge 2017.

VERNET, A. (éd.). Histoire des bibliothèques françaises. Paris 1989.

ZELZER, M.; ZELZER, K. Zur Frage der Überlieferung des Leidener Corpus philosophischer Schriften des Cicero, mit einer kritischen Bewertung karolingischer Textemendation. Wiener Studien. Wien, v. 114, p. 183214, 2001.

Tradução de Izabella Lombardi Garbellini Universidade de São Paulo 